\title{
Changes in calcium dynamics following the reversal of the sodium-calcium exchanger have a key role in AMPA receptor-mediated neurodegeneration via calpain activation in hippocampal neurons
}

\author{
IM Araújo ${ }^{\star, 1,5}$, BP Carreira ${ }^{1,5}$, T Pereira $^{1}$, PF Santos ${ }^{1}$, D Soulet ${ }^{2}$, Â Inácio ${ }^{1}$, BA Bahr ${ }^{3}$, AP Carvalho ${ }^{1}$, AF Ambrósio ${ }^{1,4}$ and CM Carvalho $^{1}$
}

Proteolytic cleavage of the $\mathrm{Na}^{+} / \mathrm{Ca}^{2+}$ exchanger (NCX) by calpains impairs calcium homeostasis, leading to a delayed calcium overload and excitotoxic cell death. However, it is not known whether reversal of the exchanger contributes to activate calpains and trigger neuronal death. We investigated the role of the reversal of the NCX in $\mathrm{Ca}^{2+}$ dynamics, calpain activation and cell viability, in $\alpha$-amino-3-hydroxy-5-methylisoxazole-4-propionate (AMPA) receptor-stimulated hippocampal neurons. Selective overactivation of AMPA receptors caused the reversal of the NCX, which accounted for approximately $30 \%$ of the rise in intracellular free calcium concentration $\left(\left[\mathrm{Ca}^{2+}\right]_{\mathrm{i}}\right)$. The NCX reverse-mode inhibitor, 2-[2-[4-(4-nitrobenzyloxy)phenyl]ethyl] isothiourea (KB-R7943), partially inhibited the initial increase in $\left[\mathrm{Ca}^{2+}\right]_{\mathrm{i}}$, and prevented a delayed increase in $\left[\mathrm{Ca}^{2+}\right]_{\mathrm{i}}$. In parallel, overactivation of AMPA receptors strongly activated calpains and led to the proteolysis of NCX3. KB-R7943 prevented calpain activation, cleavage of $\mathrm{NCX} 3$ and was neuroprotective. Silencing of $\mathrm{NCX} 3$ reduced $\mathrm{Ca}^{2+}$ uptake, calpain activation and was neuroprotective. Our data show for the first time that NCX reversal is an early event following AMPA receptor stimulation and is linked to the activation of calpains. Since calpain activation subsequently inactivates $\mathrm{NCX}$, causing a secondary $\mathrm{Ca}^{2+}$ entry, NCX may be viewed as a new suicide substrate operating in a $\mathrm{Ca}^{2+}$-dependent loop that triggers cell death and as a target for neuroprotection.

Cell Death and Differentiation (2007) 14, 1635-1646; doi:10.1038/sj.cdd.4402171; published online 22 June 2007

The sodium-calcium exchanger (NCX) plays a fundamental role in controlling $\mathrm{Na}^{+}$and $\mathrm{Ca}^{2+}$ homeostasis. ${ }^{1,2} \mathrm{NCX}$ primarily extrudes $\mathrm{Ca}^{2+}$ in exchange for $\mathrm{Na}^{+}$, whereas upon neuronal depolarization, $\mathrm{Na}^{+}$is pumped out by $\mathrm{NCX}$, while $\mathrm{Ca}^{2+}$ is pumped in. In pathophysiological conditions, overactivation of glutamate receptors can cause the reversal of NCX, leading to $\mathrm{Ca}^{2+}$ entry into the cell. ${ }^{3}$ Three NCX genes have been identified, $\mathrm{NCX} 1,{ }^{4} \mathrm{NCX} 2^{5}$ and $\mathrm{NCX} 3 .{ }^{6}$

In excitotoxic cell death, an increase in intracellular free calcium concentration $\left(\left[\mathrm{Ca}^{2+}\right]_{\mathrm{i}}\right)$ may directly cause activation of $\mathrm{Ca}^{2+}$-dependent cysteine proteases, the calpains. Calpains modulate a variety of physiological processes, ${ }^{7}$ and are important mediators of cell death. ${ }^{8,9}$ Calpains mediate the neurotoxic effect of $N$-methyl-D-aspartate (NMDA) in cultured hippocampal neurons by a caspase-independent cell death mechanism of excitotoxicity. ${ }^{10}$ Calpains are also involved in the neurotoxic effect caused by $\alpha$-amino-3-hydroxy-5-methylisoxazole-4-propionate (AMPA) receptor activation in cultured hippocampal neurons, ${ }^{11}$ and in hippocampal slice cultures. ${ }^{12}$
During excitotoxic neurodegeneration, calpains are responsible for the proteolysis of several cytoskeletal and associated proteins, kinases and phosphatases, membrane receptors and transporters. ${ }^{13}$

Recently, the involvement of calpains in the cleavage of NCX was described in cultured cerebellar granule neurons exposed to glutamate and following brain ischemia. ${ }^{14}$ The NCX3 subtype is inactivated by proteolytic cleavage by calpains, and is no longer able to pump $\mathrm{Ca}^{2+}$ out of the cell, thus enhancing cell death. Furthermore, NCX3 was shown to be more relevant for cell survival than NCX1 or NCX2, namely in cultured cerebellar granule neurons. ${ }^{14,15}$ We recently reported that neurotoxicity induced by activation of AMPA receptors is characterized by calpain activation, lack of caspase activation, nuclear condensation/fragmentation, release of cytochrome $c$ from mitochondria, decreased intracellular ATP levels, production of nitric oxide, moderate superoxide production and increased levels of peroxynitrite. $^{16-18}$ In this in vitro model of excitotoxicity, the cell

\footnotetext{
${ }^{1}$ Center for Neuroscience and Cell Biology, Department of Zoology, University of Coimbra, Coimbra, Portugal; ${ }^{2}$ Wallenberg Neuroscience Center, Department of Experimental Medical Science, Neuronal Survival Unit, Lund University, Lund, Sweden; ${ }^{3}$ Department of Pharmaceutical Sciences and the Neurosciences Program, University of Connecticut, Storrs, CT, USA and ${ }^{4}$ Center of Ophthalmology of Coimbra, IBILI, Faculty of Medicine, University of Coimbra, Coimbra, Portugal ${ }^{*}$ Corresponding author: IM Araújo, Center for Neuroscience and Cell Biology, Department of Zoology, University of Coimbra, 3004-517 Coimbra, Portugal. Tel: + 351239822752; Fax: + 351239822776; E-mail: inaraujo@cnc.cj.uc.pt

${ }^{5} \mathrm{IM}$ Araújo and BP Carreira contributed to this work equally.

Keywords: excitotoxicity; calcium; calpains; proteolysis; sodium-calcium exchanger; AMPA receptors

Abbreviations: AMPA, $\alpha$-Amino-3-hydroxy-5-methylisoxazole-4-propionate; $\left[\mathrm{Ca}^{2+}\right]_{\text {, }}$, intracellular free calcium concentration; D-AP-5, D(-)-2-amino-5-phosphonopentanoic acid; CTZ, cyclothiazide; KA, kainate; KB-R7943, 2-[2-[4-(4-nitrobenzyloxy)phenyl]] thyl]isothiourea; MAP-2, microtubule-associated protein 2; MTT, 3-(4,5dimethylthiazol-2-yl)-2,5-diphenyltetrazolium bromide; NBQX, 2,3-dioxo-6-nitro-1,2,3,4-tetrahydrobenzoquinoxaline-7-sulphonamide; NCX, sodium-calcium exchanger; NMDA, $N$-methyl-D-aspartate; nNOS, neuronal nitric oxide synthase; SBDPs, spectrin breakdown products; VSCC, voltage-sensitive $\mathrm{Ca}^{2+}$ channels

Received 16.10.06; revised 23.3.07; accepted 30.4.07; Edited by H Ichijo; published online 22.6.07
} 
death mechanisms are mostly dependent on calpains, ${ }^{11}$ providing a good model for studying calpain-dependent phenomena. Nevertheless, it is not known whether the influx of $\mathrm{Ca}^{2+}$ through reversal of the exchanger is related to activation of calpains in this model, where calpains are the main executioners of cell death, and whether inhibition of this component of $\mathrm{Ca}^{2+}$ entry during AMPA receptor activation is neuroprotective.

In this work, we investigated whether reversal of NCX is involved in the activation of calpains in cultured hippocampal neurons, as well as in the changes in $\left[\mathrm{Ca}^{2+}\right]_{i}$, proteolytic events and neuronal death, following selective activation of AMPA receptors.

\section{Results}

Blockade of NCX prevents early and delayed changes in $\left[\mathrm{Ca}^{2+}\right]_{\mathrm{i}}$. To address whether NCX is involved in the initial events of $\mathrm{Ca}^{2+}$ influx, we investigated the uptake of ${ }^{45} \mathrm{Ca}^{2+}$ in cultured hippocampal neurons, following stimulation of AMPA receptors. The excitotoxic paradigm of nondesensitizing AMPA receptor activation extensively studied was used, ${ }^{11,16,17}$ since in this model, calpains, but not caspases, are responsible for neuronal death. ${ }^{11}$ Hippocampal neurons were treated with kainate $(\mathrm{KA})(100 \mu \mathrm{M})$ for $5 \mathrm{~min}$, which is not toxic by itself in a short exposure, ${ }^{17}$ together with cyclothiazide $(\mathrm{CTZ}, 30 \mu \mathrm{M})$. CTZ is a selective blocker of AMPA receptor desensitization, ${ }^{19}$ and is a useful tool to selectively unmask effects mediated by AMPA receptors. ${ }^{16,17,20}$ 2-[2-[4-(4-nitrobenzyloxy)phenyl]ethyl] isothiourea (KB-R7943) $(20 \mu \mathrm{M})$ selectively inhibits the reverse mode of NCX and was used for this purpose, being three-fold more effective on NCX3 than on NCX1 or NCX2. ${ }^{21}$

Treatment for $5 \mathrm{~min}$ with KA plus CTZ increased ${ }^{45} \mathrm{Ca}^{2+}$ uptake to $17.3 \pm 0.59 \mathrm{nmol} \mathrm{Ca}^{2+} / 10^{6}$ cells $(P<0.001$; Figure 1a), as compared to non-stimulated hippocampal neurons $\left(1.5 \pm 0.05 \mathrm{nmol} \mathrm{Ca}^{2+} / 10^{6}\right.$ cells). Treatment with $\mathrm{KB}$ R7943 partially prevented this increase by $30 \%(P<0.001)$, while the AMPA receptor antagonist 2,3-dioxo-6-nitro-1,2,3,4tetrahydrobenzoquinoxaline-7-sulphonamide (NBQX) (10 $\mu \mathrm{M})$ completely prevented ${ }^{45} \mathrm{Ca}^{2+}$ uptake $(P<0.001)$. The effect of KB-R7943 on $\mathrm{Ca}^{2+}$ entry suggests that NCX operates in the reverse mode during the 5 min stimulation with $\mathrm{KA}$ plus $\mathrm{CTZ}$, and that $30 \%$ of the total increase in ${ }^{45} \mathrm{Ca}^{2+}$ accumulation occurred via reversal of the exchanger. ${ }^{45} \mathrm{Ca}^{2+}$ uptake in the presence of an NMDA receptor antagonist $(\mathrm{D}(-)$-2-amino5-phosphonopentanoic acid (D-AP-5), $100 \mu \mathrm{M}$ ) was similar to that of $\mathrm{KA}$ plus $\mathrm{CTZ}\left(16.9 \pm 0.11 \mathrm{nmol} \mathrm{Ca}^{2+} / 10^{6}\right.$ cells; $P>0.05$, Figure 1a), excluding the participation of NMDA receptors in the entry of $\mathrm{Ca}^{2+}$.

We next addressed the possible effect of KB-R7943 on voltage-sensitive $\mathrm{Ca}^{2+}$ channels (VSCC). Two different L-type VSCC blockers were used, nimodipine $(5 \mu \mathrm{M})$ and nitrendipine $(5 \mu \mathrm{M})$. Both drugs partially prevented ${ }^{45} \mathrm{Ca}^{2+}$ uptake upon stimulation of AMPA receptors $(8.2 \pm 0.7 \mathrm{nmol}$ $\mathrm{Ca}^{2+} / 10^{6}$ cells; $P<0.001$, and $8.5 \pm 1.1 \mathrm{nmol} \mathrm{Ca}{ }^{2+} / 10^{6}$ cells; $P<0.001$, respectively; Figure $1 \mathrm{~b}$ ). Co-treatment with either nimodipine or nitrendipine, together with KB-R7943, further decreased ${ }^{45} \mathrm{Ca}^{2+}$ uptake, as compared to KA plus CTZ, together with KB-R7943, $(P<0.001$ and $P<0.01$, respectively) or as compared to KA plus CTZ, together with nimodipine $(P<0.05)$ or nitrendipine $(P<0.05)$. These results show that the effect of KB-R7943 on the reversal of NCX is independent of VSCC.

Using single-cell analysis of the changes in $\left[\mathrm{Ca}^{2+}\right]_{i}$ by measuring Fura-2 fluorescence, we observed that exposure to KA plus CTZ for 5 min caused a mean peak increase in the fluorescence ratio of excitation (340/380) of $0.41 \pm 0.03$ (199 cells analysed, from three independent cultures) (Figure 1c). KB-R7943 decreased the mean peak increase in the fluorescence ratio to $0.25 \pm 0.05$ (164 cells analysed, from three independent cultures) (Figure 1d), as compared to KA plus CTZ alone $(P<0.05$; two-tailed $t$-test).

Furthermore, a population of cells showed a delayed sustained increase in $\left[\mathrm{Ca}^{2+}\right]_{i}$, starting approximately $40 \mathrm{~min}$ after the $5 \mathrm{~min}$ exposure to $\mathrm{KA}$, in the presence of CTZ. In cultures treated with KA plus CTZ alone, $30.1 \pm 11.9 \%$ of the cells deregulated (Figure 1c-e). In the presence of KB-R7943, only $5.9 \pm 1.4 \%$ of the cells showed a delayed increase in $\left[\mathrm{Ca}^{2+}\right]_{\mathrm{I}}(P<0.05$; two-tailed t test) (Figure 1d-f).

Blockade of NCX reversal prevents calpain activation. Several intracellular proteins are cleaved by calpains in a time-dependent manner during excitotoxic neurodegeneration, such as spectrin, ${ }^{22-25}$ neuronal nitric oxide synthase (nNOS), ${ }^{17}$ and the GluR1 subunit of AMPA receptors. ${ }^{17,26}$ In the present study, we analyzed by Western blot the effect of inhibiting the reversal of NCX on the cleavage of spectrin, nNOS and GluR1 in cultured hippocampal neurons, after non-desensitizing activation of AMPA receptors with KA. The appearance of spectrin breakdown products (SBDPs) is a marker of calpain activity during excitotoxicity. ${ }^{18,22}$ The specific SBDPs produced by calpain-mediated proteolysis are observed at molecular weights of approximately 145 and $150 \mathrm{kD}$ (Figures 2a and $\mathrm{b}$ ), after the exposure of cultured hippocampal neurons to $\mathrm{KA}(100 \mu \mathrm{M})$, in non-desensitizing conditions (CTZ present; $30 \mu \mathrm{M})$. The appearance of SBDPs corresponding to caspase activity, which would have a molecular weight of $120 \mathrm{kD}$, was not observed, confirming the absence of caspase activation. KB-R7943 prevented the appearance of the $145 \mathrm{kD}$ SBDPs (Figure 2a), as did the blockade of AMPA receptors by NBQX or the direct inhibition of calpains by MDL 28170 (Figure 2b).

The protein levels of the endogenous calpain substrates nNOS and GluR1 were also determined. We have shown previously that the levels of nNOS and GluR1 decrease after a 5 min exposure to KA plus CTZ (with a parallel increase in breakdown products for these proteins), and this effect is completely blocked by the calpain inhibitor MDL $28170 .^{17}$ Thus, nNOS and GluR1 levels can also be used as indicators of calpain activation in this model. nNOS levels decreased to $32.9 \pm 12.7 \%$ of the control after a $5 \mathrm{~min}$ exposure to $\mathrm{KA}$, in non-desensitizing conditions, and this effect was significantly prevented by KB-R7943 $(P<0.01)$ (Figure 2c). GluR1 levels decreased to $49.9 \pm 9.9 \%$ of the control after activation of AMPA receptors. KB-R7943 also significantly inhibited this effect $(P<0.01)$ (Figure $2 \mathrm{~d})$. 


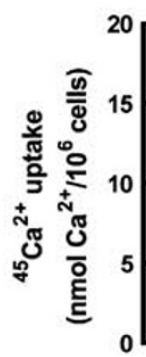

Basal
$\mathrm{KA}+\mathrm{CTZ}$
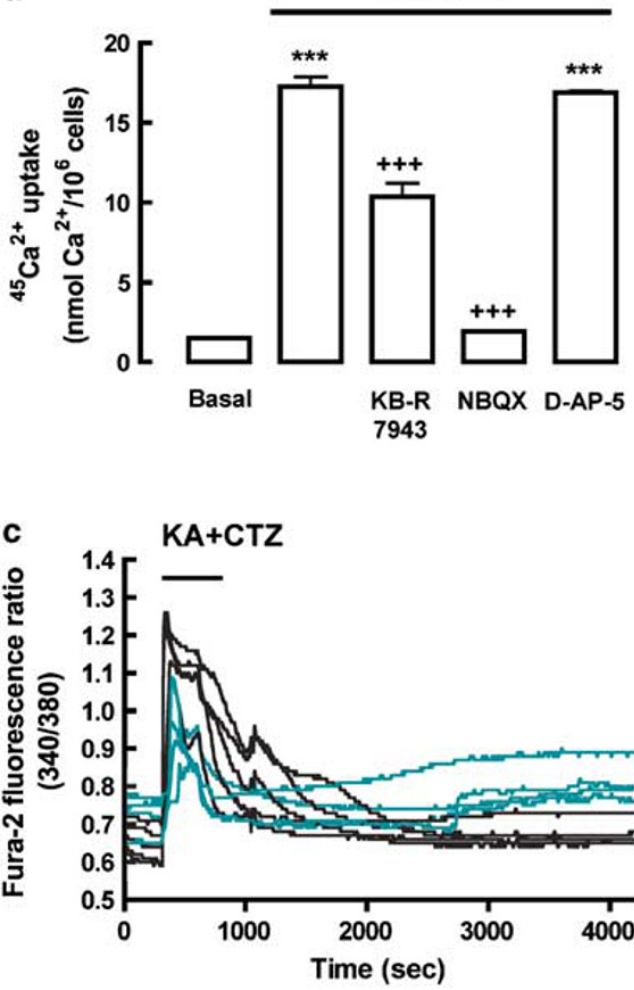

b

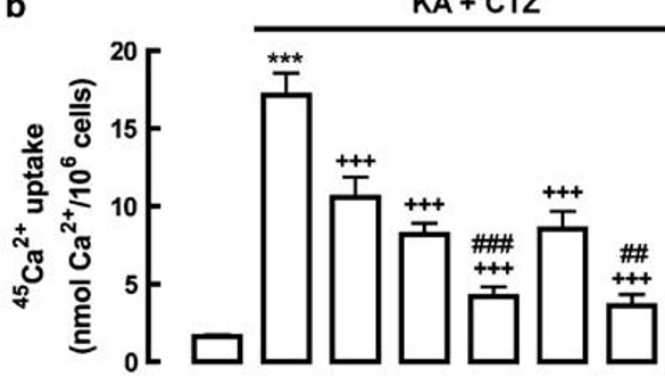

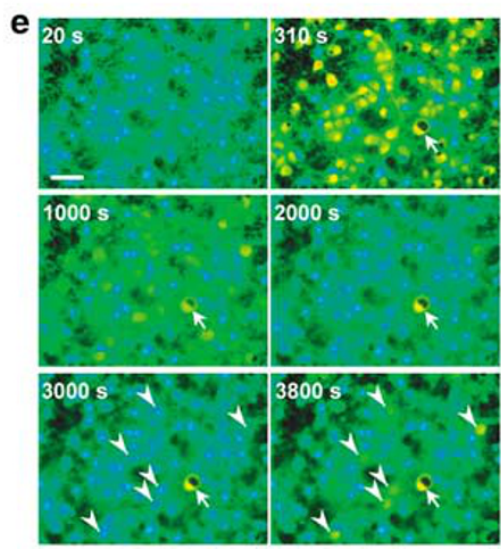

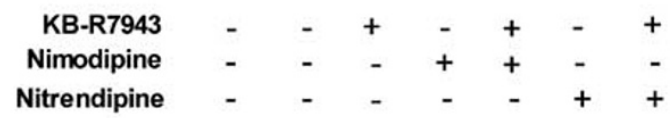

d
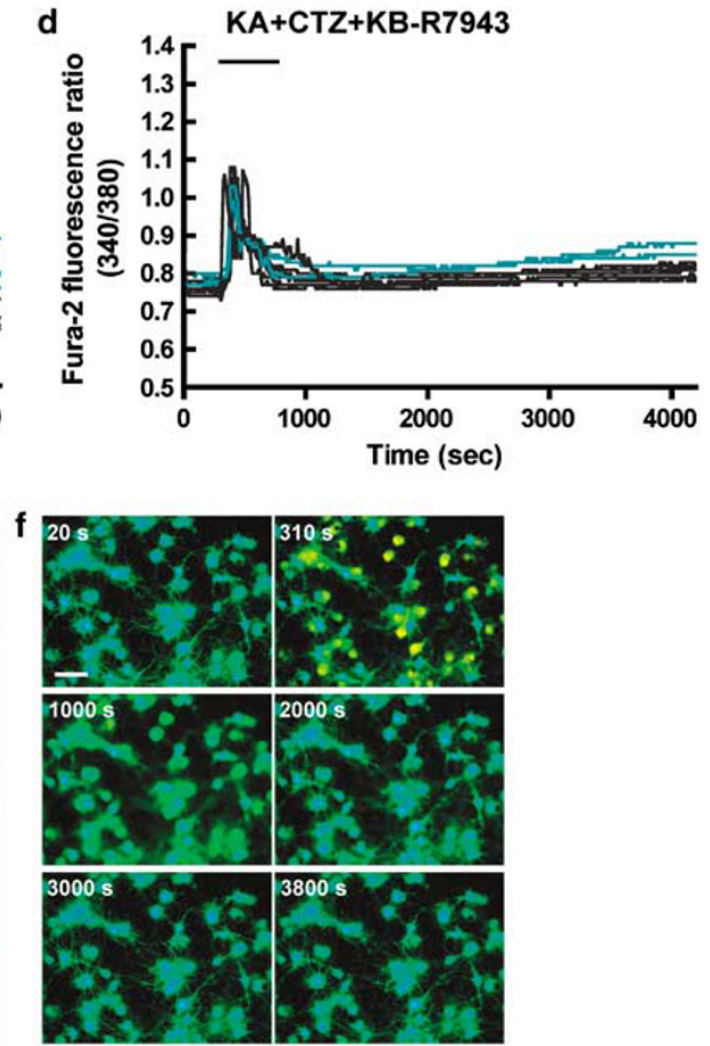

Figure 1 Effects of the blockade of the reversal of $\mathrm{NCX}$ on the changes in ${ }^{45} \mathrm{Ca}^{2+}$ uptake and on $\left[\mathrm{Ca}^{2+}\right]_{i}$ in cultured hippocampal neurons. (a) Uptake of ${ }^{45} \mathrm{Ca}{ }^{2+}$ is partially prevented by KB-R7943. The uptake of ${ }^{45} \mathrm{Ca}^{2+}$ was measured in cultured hippocampal neurons for cultures stimulated for 5 min with $\mathrm{KA}(100 \mu \mathrm{M})$ plus $\mathrm{CTZ}$ ( $\left.30 \mu \mathrm{M}\right)$. KB-R7943 $(20 \mu \mathrm{M})$ partially prevented the initial uptake of ${ }^{45} \mathrm{Ca}^{2+}$ during the exposure to the drugs, and NBQX $(10 \mu \mathrm{M})$ completely prevented the uptake of ${ }^{45} \mathrm{Ca}^{2+}$ stimulated by non-desensitizing activation of AMPA receptors. D-AP-5 $(100 \mu \mathrm{M})$ had no effect on the uptake induced by KA plus CTZ. (b) KB-R7943 does not affect ${ }^{45} \mathrm{Ca}^{2+}$ uptake mediated by VSCC. Nimodipine $(5 \mu \mathrm{M})$ or nitrendipine $(5 \mu \mathrm{M})$ (blockers of L-type VSCC) partially prevented the ${ }^{45} \mathrm{Ca}^{2+}$ uptake induced by activation of AMPA receptors, and had a cumulative effect with KB-R7943. The results are presented as nanomoles $\mathrm{Ca}^{2+} / 10^{6}$ cells, using means \pm S.E.M. of at least four independent experiments. ${ }^{* \star} P<0.001$, significantly different from control; ${ }^{+++} P<0.001$, significantly different from KA plus $\mathrm{CTZ}$; ${ }^{\# \#} P<0.01$, \#\#\# $P<0.001$, significantly different from KA plus CTZ plus KB-R7943; Bonferroni's post-test. (c, d) Representative traces of the changes in [ $\left.\mathrm{Ca}^{2+}\right]_{\mathrm{i}}$ induced by a 5 min exposure to KA plus CTZ (c) or KA plus CTZ in the presence of KB-R7943 (d), as measured by single-cell analysis of Fura-2 fluorescence in cultured hippocampal neurons. Deregulating neurons are depicted in blue. The traces are representative of at least three independent cultures, in a total of 199 neurons analysed in (c) and 164 neurons analysed in (d). Representative images of changes in Fura-2 fluorescence ratios are shown for hippocampal neurons stimulated with KA plus CTZ (e) or KA plus CTZ, in the presence of KB-R7943 (f), at different time points, as indicated in the images. Arrows show neurons that do not recover their intracellular $\mathrm{Ca}^{2+}$ levels to basal values after the exposure to $\mathrm{KA}+\mathrm{CTZ}$, and the arrowheads indicate neurons with a secondary $\mathrm{Ca}^{2+}$ increase. Scale bar, $50 \mu \mathrm{m}$

When the cultured hippocampal neurons were exposed to KA plus CTZ, rapid calpain activation was observed, as shown by the appearance of SBDPs as early as $1 \mathrm{~h}$ after the $5 \mathrm{~min}$ stimulation (Figure 3b). Concomitantly, a decrease in microtubule-associated protein 2 (MAP-2) labelling was observed. We previously characterized the rapid activation of calpains by MAP-2/SBDP double labelling that occurs following nondesensitizing activation of AMPA receptors, ${ }^{17}$ starting as early as $15 \mathrm{~min}$ after the exposure to KA plus CTZ, and peaking at $1 \mathrm{~h}$ after the exposure, so this time point was chosen to be evaluated in the present study. KB-R7943 prevented the appearance of SBDPs and the loss of MAP-2 immunoreactivity 
a

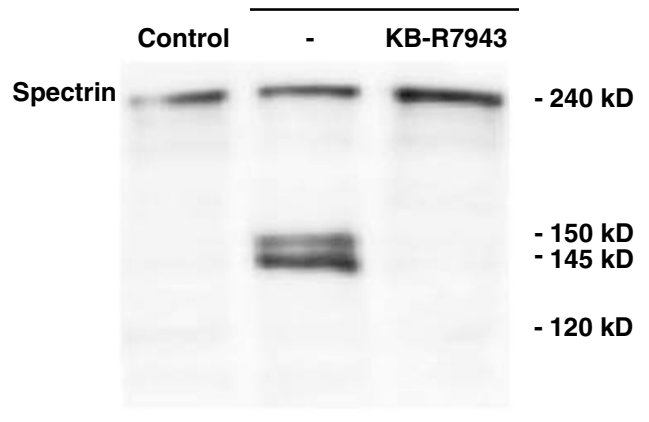

C

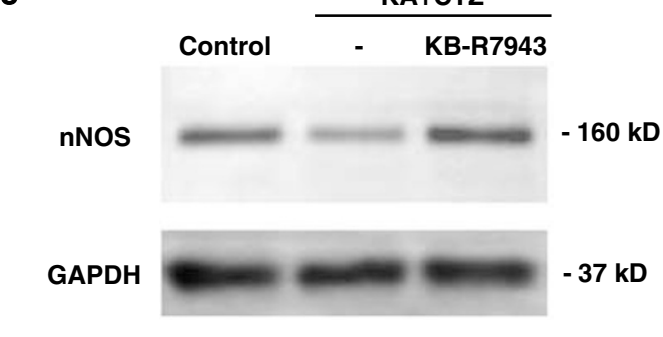

b

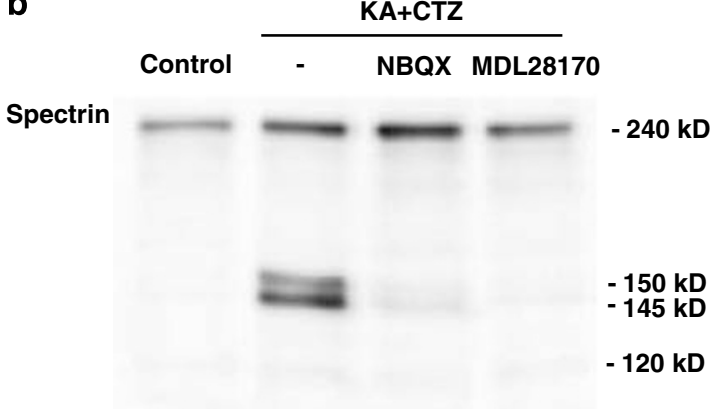

d

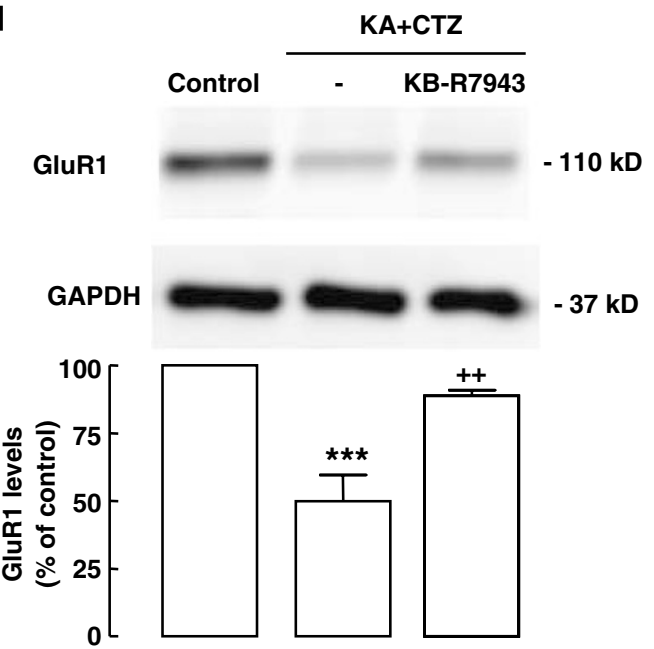

Figure 2 KB-R7943 prevents the proteolysis of the endogenous calpain substrates spectrin (a, b), nNOS (c) and GluR1 (d), $24 \mathrm{~h}$ after 5 min exposure of cultured hippocampal neurons to KA $(100 \mu \mathrm{M})$, in non-desensitizing conditions (CTZ present; $30 \mu \mathrm{M})$. The antibody used in (a) and (b) recognizes both full-length (240 kDa) and breakdown products (150 and $145 \mathrm{kDa}$ ) of spectrin (SBDPs); representative Western blots are shown. (a) Exposure to KA causes spectrin proteolysis in cultured hippocampal neurons, which is prevented by co-treatment with the NCX inhibitor KB-R7943 $(20 \mu \mathrm{M})$. (b) Either the AMPA receptor antagonist NBQX (10 $\mu \mathrm{M})$ or the calpain inhibitor (MDL 28170; $50 \mu \mathrm{M}$ ) prevented spectrin proteolysis. All panels show representative Western blots of cellular lysates. (c) Analysis of nNOS protein levels. Representative Western blots for nNOS protein levels and the loading control (GAPDH) in cellular lysates are shown and the quantification of the levels of nNOS in lysates of cultured hippocampal neurons is presented. The results are presented as percentage of control, using densitometric means \pm S.E.M. of at least three independent experiments. ${ }^{\star \star \star} P<0.001$, significantly different from control; ${ }^{++} P<0.01$, significantly different from KA plus CTZ; Bonferroni's post-test. (d) Analysis of AMPA receptor subunit GluR1 protein levels. Representative Western blots for GluR1 protein levels and the loading control (GAPDH) in cellular lysates are shown and the graph shows the quantification of the levels of GluR1 in cellular lysates. The results are presented as percentage of control, using densitometric means \pm S.E.M. of at least three independent experiments. ${ }^{* \star *} P<0.001$, significantly different from control; ${ }^{++} P<0.01$, significantly different from KA plus CTZ; Bonferroni's post-test

(Figure 3c), and significantly decreased the number of cells presenting SBDPs $(4.2 \pm 0.2 \%$ of the total number of cells, as compared to $21.4 \pm 0.8 \%$ in KA plus CTZ treated sister cultures; $P<0.001$, Bonferroni's post-test; Figure $3 \mathrm{~d}$ ), suggesting that blockade of NCX reversal prevents the activation of calpains and the subsequent appearance of SBDPs.

Since VSCC also contribute to the entry of $\mathrm{Ca}^{2+}$ following activation of AMPA receptors, we addressed the question of whether blocking this pathway would also prevent calpain activation. Interestingly, nimodipine did not prevent spectrin breakdown or the appearance of SBDPs (Figure 4a). When nimodipine was added together with KB-R7943, the effect on spectrin proteolysis was similar to that of KB-R7943 alone, suggesting that only the reversal of $\mathrm{NCX}$ is relevant for the activation of calpains, despite the fact that a similar amount of $\mathrm{Ca}^{2+}$ enters hippocampal neurons by VSCC, as shown in Figure 1b. We further explored this pathway of $\mathrm{Ca}^{2+}$ entry and analysed cell viability $24 \mathrm{~h}$ following the exposure to $\mathrm{KA}$ plus CTZ. Nimodipine had no protective effect against the toxicity of KA plus CTZ (Figure 4b), whereas co-treatment with nimodipine and KB-R7943 together $(P<0.001)$ had a neuroprotective effect similar to that of KB-R7943 alone $(P<0.001)$, suggesting that VSCC are not involved in the neurodegeneration induced by activation of AMPA receptors.

Cleavage of NCX following AMPA receptor activation. We investigated whether NCX was cleaved by calpains following non-desensitizing activation of AMPA receptors. Western blot analysis showed that NCX3, but not NCX1 or NCX2, underwent a proteolytic cleavage following exposure to $\mathrm{KA}$ (5 min exposure, followed by $24 \mathrm{~h}$ recovery), in non-desensitizing conditions (Figure 5a). KBR7943 prevented the proteolysis of NCX3. MDL 28170 also prevented the appearance of the $60 \mathrm{kDa}$ NCX3 breakdown product, suggesting that calpains are likely responsible for this phenomenon (Figure 5b). An hour after the stimulus, it 

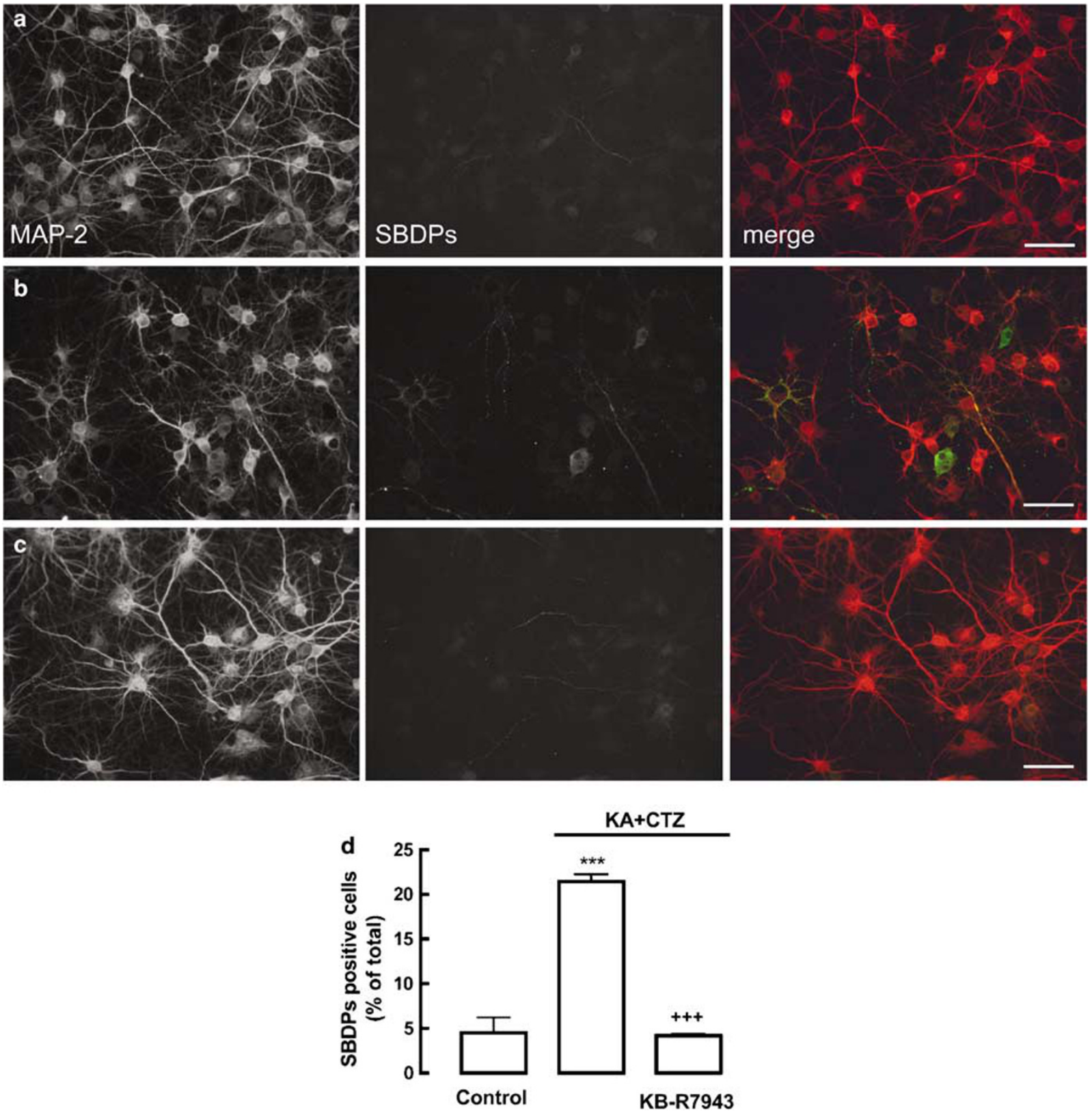

Figure 3 Blockade of NCX prevents the appearance of SBDPs and the loss of MAP-2 immunostaining in cultured hippocampal neurons 60 min after a 5 min exposure to KA $(100 \mu \mathrm{M})$, in non-desensitizing conditions (CTZ present; $30 \mu \mathrm{M}$ ). (a) Control, (b) KA plus CTZ and (c) KA plus CTZ, in the presence of KB-R7943 (20 $\mu \mathrm{M})$. MAP-2 labels neuronal cells, particularly at the level of the neuritic network (red). Treatment with KB-R7943 prevents the appearance of SBDPs (green) following activation of AMPA receptors (c, similar to control culture in a). Scale bar, $50 \mu \mathrm{m}$. (d) KB-R7943 decreases the number of cells showing SBDPs. The results are presented as percentage of total number of cells, using means \pm S.E.M. of at least three independent experiments. ${ }^{\star \star \star} P<0.001$, significantly different from control; ${ }^{++}{ }^{+} P<0.001$, significantly different from KA plus CTZ; Bonferroni's post-test

was already evident the presence of NCX3 breakdown products and of SBDPs (Figure 5c), which were also blocked by KB-R7943.

\section{Blockade of NCX by KB-R7943 prevents the neurotoxic} effect of KA in non-desensitizing conditions. In order to find whether NCX plays a role following AMPA receptor activation, we next examined the potential neuroprotective effect of blocking NCX reversal during exposure to KA plus
CTZ. A 5 min exposure decreased the reduction of 3-(4,5dimethylthiazol-2-yl)-2,5-diphenyltetrazolium bromide (MTT) to $81.8 \pm 1.5 \%$ of the control $(P<0.001), 24 \mathrm{~h}$ after the exposure to the drugs (Figure 6a). In the presence of KBR7943, the reduction of MTT following exposure to KA plus CTZ was similar to that in control conditions $(90.2 \pm 3.2 \%$ of the control; $P<0.05)$. KB-R7943 alone did not affect the viability of the cultures. Nuclear condensation was also evaluated as a measure of cell death. Cells showing nuclear 
a

KB-R7943

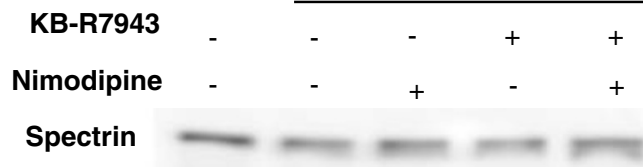

$-240 k D$

$-145 / 150 \mathrm{kD}$

$-120 \mathrm{kD}$
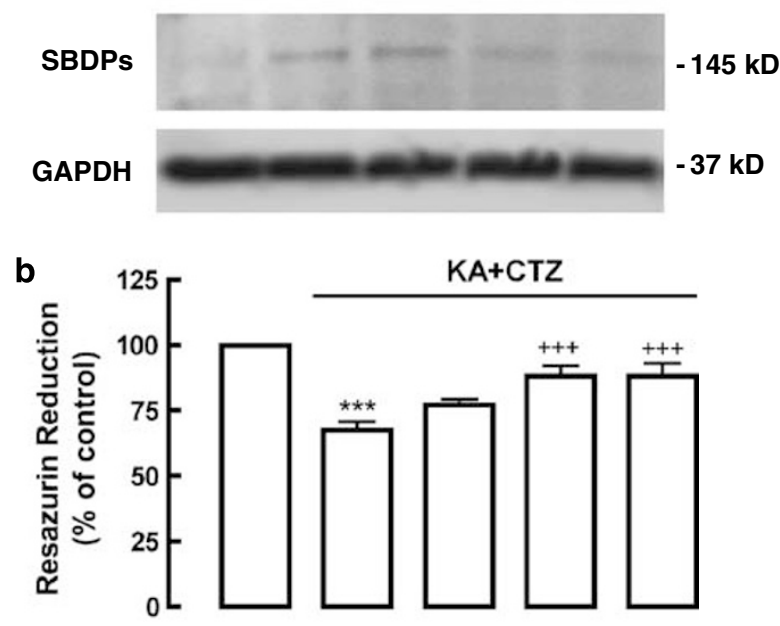

KB-R7943

Nimodipine

Figure 4 Blockade of VSCC by nimodipine $(5 \mu \mathrm{M})$ does not prevent proteolysis of spectrin following activation of AMPA receptors and is not neuroprotective. (a) Co-stimulation of AMPA receptors (with KA plus CTZ, for $5 \mathrm{~min}$ ) together with nimodipine did not prevent cleavage of spectrin, or the appearance of SBDPs, as shown in representative Western blot images, obtained from cellular lysates $1 \mathrm{~h}$ following the exposure to the drugs. (b) Nimodipine did not prevent the decrease in cell viability following exposure to $\mathrm{KA}$ plus $\mathrm{CTZ}, 24 \mathrm{~h}$ after exposure to the drugs, as assessed by the resazurin reduction assay. Addition of nimodipine, when KB-R7943 was present, had a effect similar to that of KB-R7943 alone. The results are presented as percentage of control, using means \pm S.E.M. of at least four independent experiments. ${ }^{* * *} P<0.001$, significantly different from control; $+++P<0.001$, significantly different from KA plus CTZ; Bonferroni's post-test

condensation/fragmentation were considered dead, ${ }^{27}$ and the number of condensed nuclei in untreated cultures was similar to what was previously observed by others in cultured hippocampal neurons after 7 days in culture. ${ }^{27}$ Hippocampal neurons treated with KA plus CTZ for $5 \mathrm{~min}$ showed a higher number of condensed nuclei $(37.4 \pm 1.8 \% ; P<0.05)$, compared with control cultures $(21.3 \pm 1.7 \%)$ (Figure $6 b-\mathrm{e})$. KB-R7943 prevented this effect $(27.5 \pm 2.0 \% ; P<0.05)$, suggesting that reversal of NCX has deleterious consequences. NBQX was used as a positive control for neuroprotection, ${ }^{11}$ and the number of condensed nuclei was similar to control conditions.

KB-R7943 is considered more selective for NCX3 than for NCX1 or NCX2. To our knowledge, there are no selective blockers of the NCX2 reverse mode, but such an inhibitor is available for NCX1. In order to better understand whether NCX1 participates in the excitotoxic cell death elicited by activation of AMPA receptors, we used SN-6, which showed improved preference for the reverse mode of NCX1. ${ }^{26}$ In the range of 10 to $50 \mu \mathrm{M}, \mathrm{SN}-6$ did not prevent cell death induced by activation of AMPA receptors (Figure 7). SN-6 (1-30 $\mu \mathrm{M})$ also did not prevent the ${ }^{45} \mathrm{Ca}^{2+}$ uptake induced by KA plus CTZ, nor did it prevent calpain activation (Figure 7). These results suggest that the NCX1 subtype is not the main NCX subtype involved in the neurotoxic effect of AMPA receptor activation, thus reinforcing the possibility that NCX3 is preferentially involved in these mechanisms.

Silencing of $\mathrm{NCX} 3$ reduces $\mathrm{Ca}^{2+}$ uptake and decreases calpain activation. To confirm the preferential involvement of $\mathrm{NCX} 3$ in the initial $\mathrm{Ca}^{2+}$ influx suggested by the use of pharmacological inhibitors, NCX3 was silenced using siRNA delivery. siRNA transfection to hippocampal neurons was optimized using a non-silencing siRNA sequence conjugated with Alexa Fluor 488 (green). Cells were transfected 5 days after plating, and $48 \mathrm{~h}$ after the transfection procedure labelled and viable hippocampal neurons were observed, as compared to mock-transfected cultures (no siRNA) (Figure 8a). Transfection efficacy was evaluated using a control siRNA against a housekeeping control gene, GAPDH, showing that $10 \mathrm{nM}$ of siRNA-GAPDH decreased GAPDH protein levels after $48 \mathrm{~h}$ to $50 \%$ of control (mocktransfected cells) (Figure 8b). siRNA-NCX3 (at 10 or $50 \mathrm{nM}$ ) decreased NCX3 protein levels by 20 and $50 \%$, respectively (Figure 8c). We observed that siRNA-NCX3-transfected cells had a smaller ${ }^{45} \mathrm{Ca}^{2+}$ uptake during exposure to $\mathrm{KA}$ plus CTZ $\left(10.1 \pm 0.5 \mathrm{nmol} \mathrm{Ca}{ }^{2+} / 10^{6}\right.$ cells, and $9.5 \pm 0.4 \mathrm{nmol}$ $\mathrm{Ca}^{2+} / 10^{6}$ cells, for 10 or $50 \mathrm{nM}$ siRNA-NCX3, respectively; $P<0.01$ and $P<0.001$, respectively), as compared to mocktransfected cells $\left(12.2 \pm 0.8 \mathrm{nmol} \mathrm{Ca}{ }^{2+} / 10^{6}\right.$ cells) (Figure $8 \mathrm{e}$ ). Cells transfected with a non-silencing scrambled control siRNA had a ${ }^{45} \mathrm{Ca}^{2+}$ uptake similar to mock-transfected cells. ${ }^{45} \mathrm{Ca}^{2+}$ uptake in unstimulated cells was similar to all conditions.

Silencing of NCX3 also caused a decrease in spectrin proteolysis, as compared to mock-transfected cells (Figure 8d), and had a neuroprotective effect on hippocampal neurons, $24 \mathrm{~h}$ after the exposure to KA plus CTZ (Figure 8f). The decrease in cell viability observed in mock-transfected cells upon exposure to KA plus CTZ was significantly prevented by $50 \mathrm{nM}$ siRNA-NCX3 $(P<0.01$, as compared to mock-transfected cells).

\section{Discussion}

In this work, we show that inhibition of the reversal of NCX reduced the initial increase in intracellular $\mathrm{Ca}^{2+}$ in cultured hippocampal neurons and also decreased the number of cells showing a secondary $\mathrm{Ca}^{2+}$ overload. The reversal of NCX activated calpains, but not caspases, and decreased cell viability upon exposure to $K A$, in non-desensitizing conditions. Blocking the reversal of NCX during AMPA receptor overactivation prevented the activation of calpains, the cleavage of the NCX3, and was neuroprotective. Although VSCC contribute to the initial $\mathrm{Ca}^{2+}$ entry during AMPA receptor stimulation, $\mathrm{Ca}^{2+}$ entry through VSCC does not contribute to calpain activation or cell death. Furthermore, selective 

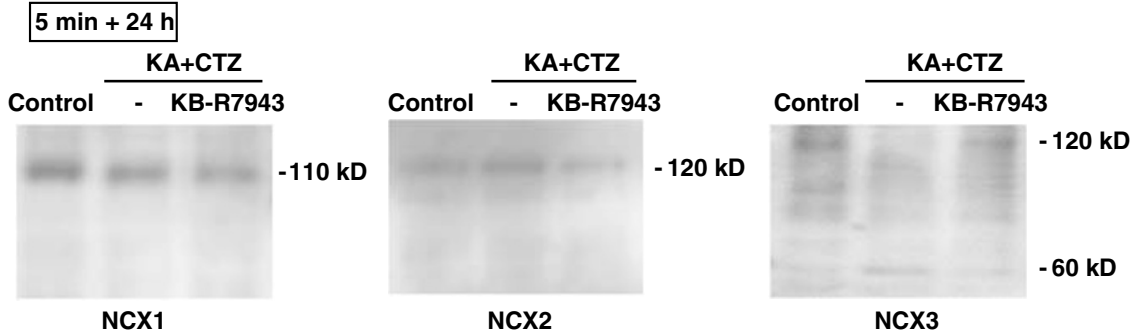

b

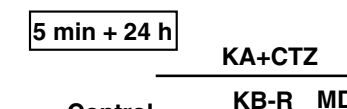

NCX3 \begin{tabular}{lll} 
Control & $-\quad$ KB-R MDL \\
\cline { 2 - 2 } & 794328170
\end{tabular} NCX3 Breakdown
Product

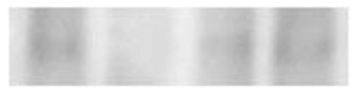

$-120 \mathrm{kD}$ $-60 k D$ c

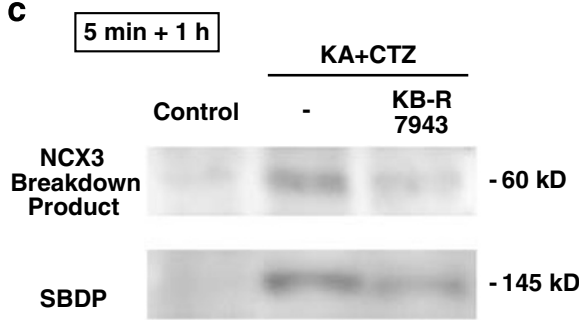

Figure 5 Cleavage of NCX in cultured hippocampal neurons. (a) Proteolysis of NCX3 following exposure to KA (100 $\mu \mathrm{M}$ ) plus CTZ (30 $\mu \mathrm{M})$ for 5 min (followed by a $24 \mathrm{~h}$ recovery), in cultured hippocampal neurons, produced an NCX3 breakdown product of approximately $60 \mathrm{kDa}$, which was prevented by KB-R7943 (20 $\mu \mathrm{M})$. NCX1 and NCX2 were not cleaved. Representative Western blots for the three NCX subtypes are shown. (b) MDL $28170(50 \mu \mathrm{M})$, the calpain inhibitor, also prevented the NCX3 proteolysis caused by a $5 \mathrm{~min}$ exposure to KA plus CTZ, followed by a $24 \mathrm{~h}$ recovery period. (c) An hour after the 5 min exposure to KA plus CTZ, the appearance of breakdown products of NCX3 was already clear, as well as the appearance of SBDPs (using the antibody against SBDPs), which were prevented by KB-R7943

silencing of NCX3 by siRNA-NCX3 clearly produced similar results to those of pharmacological blockade of reversal of NCX by KB-R7943, either in reducing $\mathrm{Ca}^{2+}$ entry, calpain activation or cell death.

Inhibition of the reversal of NCX by KB-R7943, during activation of AMPA receptors in cultured hippocampal neurons, decreased the initial amount of $\mathrm{Ca}^{2+}$ entering the neurons and decreased the number of cells showing a delayed increase in $\left[\mathrm{Ca}^{2+}\right]_{i}$, showing that this route of $\mathrm{Ca}^{2+}$ entry significantly contributes to the overall increase in $\left[\mathrm{Ca}^{2+}\right]_{i}$ during stimulation of AMPA receptors. In excitotoxic conditions, delayed $\mathrm{Ca}^{2+}$ deregulation usually develops. It is characterized by a dramatic increase in $\left[\mathrm{Ca}^{2+}\right]_{i}$ following the activation of $\mathrm{Ca}^{2+}$-permeable receptors, particularly glutamate receptors, even after the stimulus has ended, thought to be due to loss of the mitochondrial ability to buffer intracellular $\mathrm{Ca}^{2+} \cdot{ }^{28-31}$ More recently, it was demonstrated that, in cerebellar granule neurons, NCX also participates in this process of secondary $\mathrm{Ca}^{2+}$ overload, ${ }^{14}$ due to its loss of the ability to pump $\mathrm{Ca}^{2+}$ out of the cell, following its proteolytic inactivation by calpains upon exposure to glutamate, providing a new hypothesis for the origin of delayed $\mathrm{Ca}^{2+}$ deregulation. Hoyt et al. ${ }^{32}$ have shown in cultured rat forebrain neurons that, although reversal of NCX contributes to $\mathrm{Ca}^{2+}$ transients and to the immediate rise in intracellular $\mathrm{Ca}^{2+}$ levels upon exposure to glutamate, it has no effect in the mean peak increase caused by a prolonged exposure to glutamate nor does it contribute to neuronal injury. In Purkinje cerebellar neurons, NCX also contributes to $\mathrm{Ca}^{2+}$ transients upon activation of AMPA receptors, although the consequences for cell viability were not addressed. ${ }^{33}$ Here we show, for the first time, that in conditions of selective activation of AMPA receptors, NCX contributes not only to initial $\mathrm{Ca}^{2+}$ influx but also to a delayed increase in intracellular $\mathrm{Ca}^{2+}$, following the
AMPA receptor activation in hippocampal neurons. This increase is not as dramatic as the canonical delayed $\mathrm{Ca}^{2+}$ deregulation but, nevertheless, a significant population of cells present a sustained increased in $\left[\mathrm{Ca}^{2+}\right]_{i} 30-40$ min after the stimulation with KA plus CTZ.

Blockade of the reversal of NCX prevented activation of calpains, which occurs shortly after non-desensitizing activation of AMPA receptors in cultured hippocampal neurons. Calpain activation can be detected as early as 15-30 min following stimulation in this model of excitotoxicity, ${ }^{11}$ suggesting that calpain activation occurs before the delayed increase in intracellular $\mathrm{Ca}^{2+}$ levels, and depends on the initial rise in $\mathrm{Ca}^{2+}$. Blocking the NCX reversal only partially prevented the initial increase in $\left[\mathrm{Ca}^{2+}\right]_{i}$, although it appears to be enough to prevent activation of calpains and, thus, protect the cells from dying. The measurement of $\mathrm{Ca}^{2+}$ changes and evaluation of calpain activation clearly show that blocking the reversal of NCX is essential and sufficient to prevent calpain activation and the subsequent downstream events, like the delayed increase in intracellular $\mathrm{Ca}^{2+}$ and the cleavage of endogenous calpain substrates like NCX3.

The present study also shows that blocking the reversal of NCX during stimulation of AMPA receptors affords neuroprotection against cell death. Inhibition of NCX reversal or silencing of NCX3 prevented the decrease in cell viability that characterizes a short-term exposure to KA plus CTZ, an effect similar to that of pharmacologically inhibiting calpains, described earlier in the same model as used in this study. ${ }^{11}$ Blocking the reversal of NCX prevents activation of calpains, stops excitotoxic cell death upstream of the calpain proteolytic system and downstream of ionotropic glutamate receptors. Blocking either reversal of NCX or VSCC prevented $\mathrm{Ca}^{2+}$ entry by approximately the same extent. Reversal of NCX clearly contributes to calpain activation, but $\mathrm{Ca}^{2+}$ entering 
a

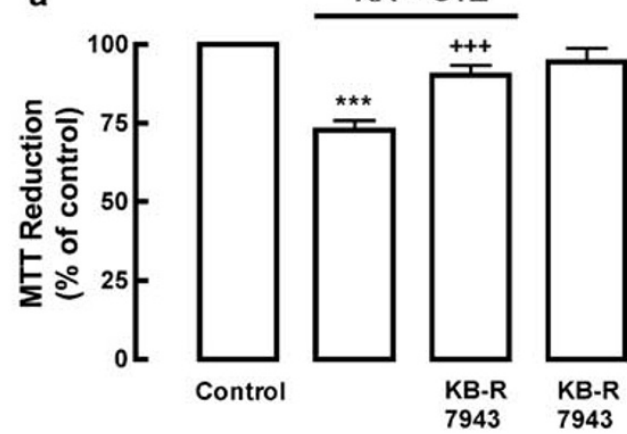

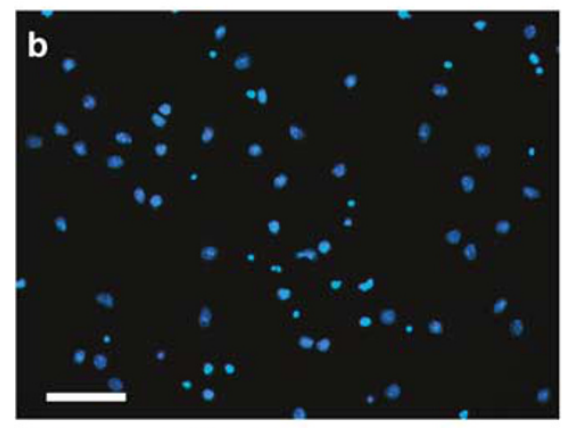

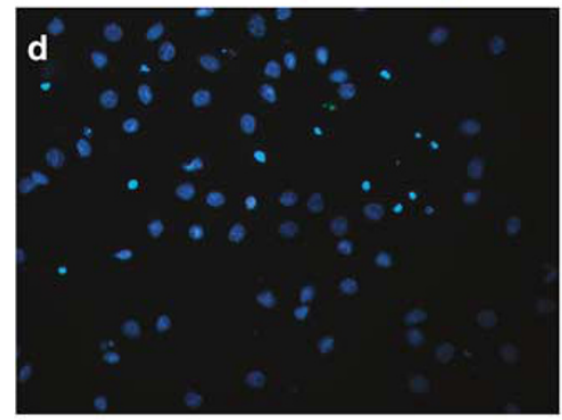

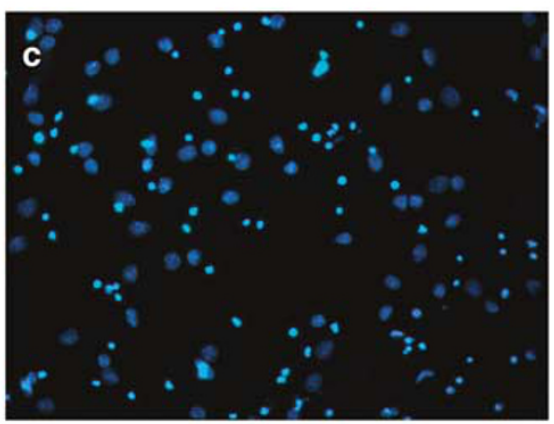

e

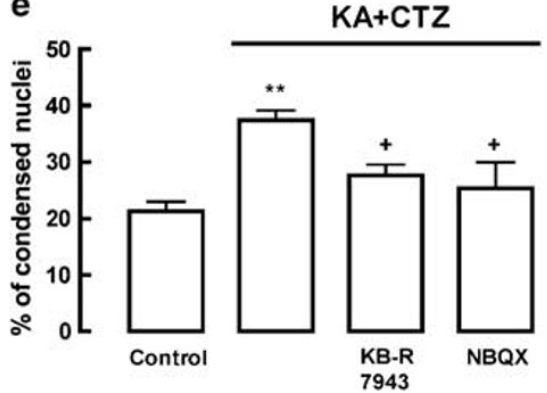

Figure 6 KB-R7943 $(20 \mu \mathrm{M})$ protects against the neurotoxicity induced by KA, in non-desensitizing conditions (CTZ present). Cell viability was evaluated by the MTT reduction assay (a), and nuclear condensation was assessed by Hoechst 33342 nuclear staining (b-e). Cultured hippocampal neurons were exposed to KA (100 $\mu \mathrm{M})$ plus $\mathrm{CTZ}(30 \mu \mathrm{M})$ for $5 \mathrm{~min}$, in the presence or absence of KB-R7943 $(20 \mu \mathrm{M})$, followed by a $24 \mathrm{~h}$ recovery period. (a) KB-R7943 prevented the decrease in MTT reduction following activation of AMPA receptors, as depicted in the graph. The results are presented as percentage of control (no drug), and are expressed as means \pm S.E.M. of at least five independent experiments, performed in triplicate. ${ }^{* \star} P<0.001$, significantly different from control; ${ }^{+}++P<0.001$, significantly different from KA plus CTZ; Bonferroni's posttest. KB-R7943 also prevented the increase in nuclear condensation following activation of AMPA receptors: (b) Control, (c) KA plus CTZ and (d) KA plus CTZ, in the presence of KB-R7943. Scale bar, $50 \mu \mathrm{m}$. (e) The results are presented as percentage of the number of condensed nuclei, and are expressed as means \pm S.E.M. of at least four independent experiments. NBQX $(10 \mu \mathrm{M})$ was used to completely block AMPA receptors, as a positive control for full neuroprotection. ${ }^{*} P<0.05$, significantly different from control; ${ }^{+} P<0.05$, significantly different from KA plus CTZ; Bonferroni's post-test

through VSCC does not activate calpains and has no influence in promoting cell death. This observation is in agreement with previous studies by other groups, showing that the VSCC pathway of $\mathrm{Ca}^{2+}$ entry is not particularly toxic to cells ${ }^{34}$ or involved in calpain activation. ${ }^{35} \mathrm{Ca}^{2+}$ entering the cell by specific entry points is more efficient in triggering cell death than other pathways - source-specificity hypothesis. ${ }^{36}$ Up to now, $\mathrm{Ca}^{2+}$-permeable glutamate receptors were considered to be associated with source-specific toxicity, particularly NMDA receptors. Our study shows that AMPA receptor-mediated toxicity involves in its early stages a specific influx pathway for toxic $\mathrm{Ca}^{2+}$ that is not a member of the glutamate receptor family, the $\mathrm{Na}^{+} / \mathrm{Ca}^{2+}$ exchanger, and that appears to be a key factor in committing the cells to live or die.
Several aspects of the role of NCX in neuronal physiology have recently been reviewed by others, ${ }^{37}$ emphasizing the relevance of $\mathrm{NCX}$ for the regulation of neuronal $\left[\mathrm{Ca}^{2+}\right]_{i}$ and for the prevention of the pathological $\mathrm{Ca}^{2+}$ overload. As summarized in Figure $9, \mathrm{Ca}^{2+}$ entry during activation of AMPA receptors (Figure 9a) occurs in part through the reversal of the NCX (Figure 9b) and contributes to cell death by causing activation of calpains (Figure 9c), which then leads to the cleavage of several cellular proteins, including NCX (Figure 9d), causing the secondary $\mathrm{Ca}^{2+}$ increase due to impaired $\mathrm{Ca}^{2+}$ extrusion and finally neuronal cell death. Possibly, the secondary increase in $\mathrm{Ca}^{2+}$ shifts calpain activation from a transitory to a sustained active state. We also show that $\mathrm{Ca}^{2+}$ entry through the reversal of $\mathrm{NCX}$ contributes more relevantly to calpain activation and cell 


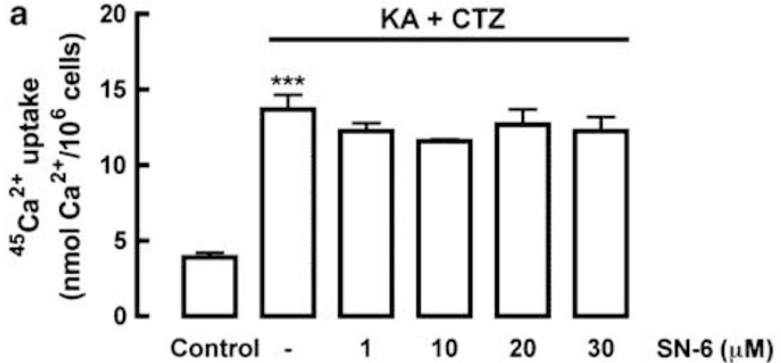

b
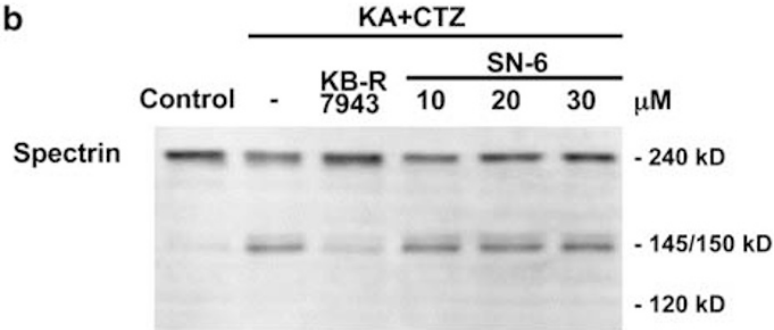

C

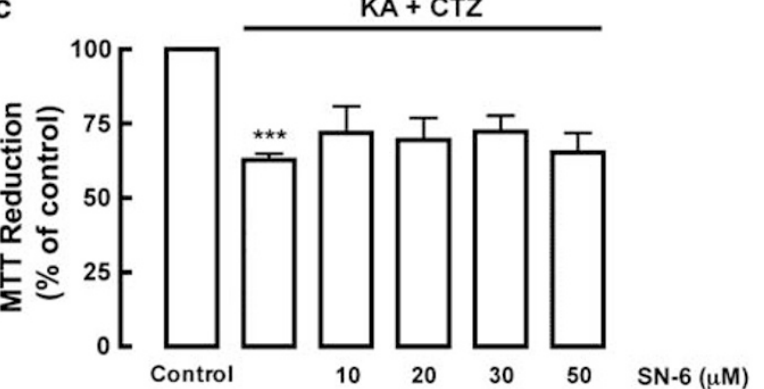

Figure 7 Lack of effect of SN-6, the reverse-mode inhibitor selective for NCX1, in calcium uptake, calpain activation and cell death, following activation of AMPA receptors. (a) SN-6 neither blocked ${ }^{45} \mathrm{Ca}^{2+}$ uptake up to $30 \mu \mathrm{M}$, nor did it prevent proteolysis of spectrin (b). Cell viability was also not changed by SN-6, up to $50 \mu \mathrm{M}$ (c). The results are presented as nanomoles $\mathrm{Ca}^{2+} / 10^{6}$ cells (a), or as percentage of control (c), using means + S.E.M. of at least four independent experiments. ${ }^{* *} P<0.001$, significantly different from control; Bonferroni's post-test

death, than $\mathrm{Ca}^{2+}$ entering the cell by other pathways, such as the VSCC, showing that toxic $\mathrm{Ca}^{2+}$ enters the cell at specific entry points. In this model, NCX appears to work in a $\mathrm{Ca}^{2+}$ loop that culminates with its own proteolysis and inactivation. NCX can be considered as a new suicide substrate for calpains during excitotoxic cell death induced by activation of AMPA receptors, since its reversal triggers a chain of events that result in NCX proteolysis and inactivation, contributing to a secondary increase in $\left[\mathrm{Ca}^{2+}\right]_{i}$ (Figure $\left.9 \mathrm{e}\right)$, and ultimately neuronal demise. Blockade of the reversal of the NCX system may be considered as a therapeutic target for neuroprotection upstream of intracellular events, following AMPA receptor overactivation in pathophysiological conditions.

\section{Materials and Methods}

Materials. Neurobasal medium, B27 supplement, gentamicin and trypsin (USP grade) were purchased from GIBCO BRL, Life Technologies, Scotland. Mouse antiMAP-2, glutamate, glutamine, DNase (DN-25), PMSF, dithiothreitol, chymostatin leupeptin, antiparin, pepstatin A and trypan blue were purchased from Sigma
Chemical (St Louis, MO, USA). Kainate, ciclothiazide, KB-R7943, SN-6 and NBQX were obtained from Tocris (Bristol, UK). MDL 28170 was purchased from Bachem (Bubendorf, $\mathrm{CH}$ ). Mouse monoclonal anti-nNOS was purchased from Transduction Laboratories (San Jose, CA, USA) and mouse monoclonal anti-spectrin (full-length protein) was obtained from Chemicon. Rabbit polyclonal anti-GluR1 was purchased from Upstate Biotechnology (Charlottesville, VA, USA). Rabbit polyclonal anti-NSBDP was raised against end residues Gln-Gln-Glu-Val-Tyr of the aminoterminal spectrin fragment produced by calpain I. ${ }^{38}$ Antibodies selective for NCX1 (clone R3F1) and NCX3 were developed by Dr Kenneth Philipson, ${ }^{39}$ and the antibody selective for NCX2 (clone W1C3) was developed by Dr Harmut Porzig. ${ }^{39}$ Anti-mouse IgG labelled with Alexa Fluor 488 or 594 and anti-rabbit IgG labelled with Alexa Fluor 488 or 594 were purchased from Molecular Probes (Leiden, The Netherlands). Polyvinylidene difluoride (PVDF) membranes, alkaline phosphatase-linked anti-mouse secondary antibodies, ${ }^{45} \mathrm{Ca}^{2+}$ and the Enhanced Chemifluorescence (ECF) reagent were obtained from Amersham Pharmacia Biotech (Buckinghamshire, UK). Other reagents used in immunoblotting experiments were purchased from BioRad. All other reagents were from Sigma or from Merck KGaA (Darmstadt, Germany).

Primary hippocampal cultures. Hippocampal neurons were dissociated from hippocampi of E18-E19 Wistar rat embryos, after treatment with trypsin $\left(2.0 \mathrm{mg} / \mathrm{ml}, 15 \mathrm{~min}, 37^{\circ} \mathrm{C}\right)$ and deoxyribonuclease I $(0.15 \mathrm{mg} / \mathrm{ml})$ in $\mathrm{Ca}^{2+}{ }_{-}$, and $\mathrm{Mg}^{2+}$, free Hank's balanced salt solution (137 mM NaCl, $5.36 \mathrm{mM} \mathrm{KCl}, 0.44 \mathrm{mM}$ $\mathrm{KH}_{2} \mathrm{PO}_{4}, 0.34 \mathrm{mM} \mathrm{Na}_{2} \mathrm{PO}_{4} \cdot 2 \mathrm{H}_{2} \mathrm{O}, 4.16 \mathrm{mM} \mathrm{NaHCO}, 5 \mathrm{mM}$ glucose, $1 \mathrm{mM}$ sodium pyruvate, $10 \mathrm{mM}$ HEPES, $\mathrm{pH}$ 7.4). The cells were cultured in serum-free Neurobasal medium, supplemented with B27 supplement, glutamate $(25 \mu \mathrm{M})$, glutamine $(0.5 \mathrm{mM})$ and gentamicin $(0.12 \mathrm{mg} / \mathrm{ml})$, as described previously. ${ }^{16,17,22}$ Cultures were kept at $37^{\circ} \mathrm{C}$ in a humidified incubator in $5 \% \mathrm{CO}_{2} / 95 \%$ air, for $7-8$ days, the time required for maturation of hippocampal neurons. The cells were plated on poly-D-lysine-coated $(0.1 \mathrm{mg} / \mathrm{ml})$ multiwells at a density of $0.1 \times 10^{6}$ cells/ $\mathrm{cm}^{2}$, for Western Blot analysis, MTT reduction and ${ }^{45} \mathrm{Ca}^{2+}$ uptake assays, and plated on coverslips at a density of $0.032 \times 10^{6} \mathrm{cells} / \mathrm{cm}^{2}$ for immunocytochemistry, staining of condensed nuclei and single-cell calcium imaging.

Exposure of hippocampal neurons to drugs. Hippocampal neurons were exposed to KA $(100 \mu \mathrm{M})$ and cyclothiazide (CTZ; $30 \mu \mathrm{M})$ for $5 \mathrm{~min}$, and were allowed to recover in culture, for $24 \mathrm{~h}$. Briefly, the cells were carefully washed twice with Krebs buffer ( $132 \mathrm{mM} \mathrm{NaCl}, 4 \mathrm{mM} \mathrm{KCl}, 1.4 \mathrm{mM} \mathrm{MgCl}, 1 \mathrm{mM} \mathrm{CaCl}, 6 \mathrm{mM}$ glucose, $10 \mathrm{mM}$ Hepes-Na, $\mathrm{pH}$ 7.4) after the incubation period with the drugs, and then further incubated without drugs for $24 \mathrm{~h}$ in supplemented Neurobasal medium. The drugs were diluted in small aliquots of conditioned medium and then added back to the correspondent well. Particularly, the calpain inhibitor MDL 28170 $(50 \mu \mathrm{M})$, was added $15 \mathrm{~min}$ before, maintained throughout the incubation period and during the $24 \mathrm{~h}$ recovery period in supplemented Neurobasal medium. The ionotropic glutamate receptor antagonist, 2,3-dioxo-6-nitro-1,2,3,4-tetrahydrobenzoquinoxaline-7-sulphonamide (NBQX; $10 \mu \mathrm{M}$ ), SN-6 or the reversemode selective NCX inhibitor KB-R7943 $(20 \mu \mathrm{M})$ were added during the exposure to KA plus CTZ.

Assessment of cell viability. Cell viability was assessed after exposure of cultured hippocampal neurons to drugs using either the MTT or the resazurin reduction assays. MTT, when taken up by living cells, is converted by cellular dehydrogenases from a yellow to a water-insoluble blue-coloured precipitate. ${ }^{23}$ Briefly, Krebs buffer with MTT $(0.5 \mathrm{mg} / \mathrm{ml})$ was added to the cultures and incubated for $1 \mathrm{~h}$ at $37^{\circ} \mathrm{C}$ in the incubation chamber. The precipitated dye was dissolved in $0.04 \mathrm{M} \mathrm{HCl}$ in isopropanol and spectrophotometrically (absorbance at $570 \mathrm{~nm}$ ) quantitated. All experiments were carried out in triplicate.

Resazurin reduction was measured spectrophotometrically at 570 and $600 \mathrm{~nm}$, following addition of $10 \%$ resazurin (in phosphate-buffered saline (PBS)) to the culture medium. The cultures were incubated with $10 \%$ resazurin for $2 \mathrm{~h}$ at $37^{\circ} \mathrm{C}$, in the dark, and then the media absorbance was quantified. All the experiments were carried out in duplicate (two independent wells per condition), and the results are expressed as percentage of control.

Evaluation of nuclear condensation. Hippocampal neurons plated on coverslips were fixed with $4 \%$ paraformaldehyde after incubation with drugs. Briefly, Hoechst $33342(2 \mu \mathrm{g} / \mathrm{ml})$ in PBS was added to the cultures and incubated for $10 \mathrm{~min}$ at room temperature, as previously described. ${ }^{27}$ The coverslips were mounted in slides using Dako fluorescent mounting medium (Dako, Glastrup, Denmark). The 
a
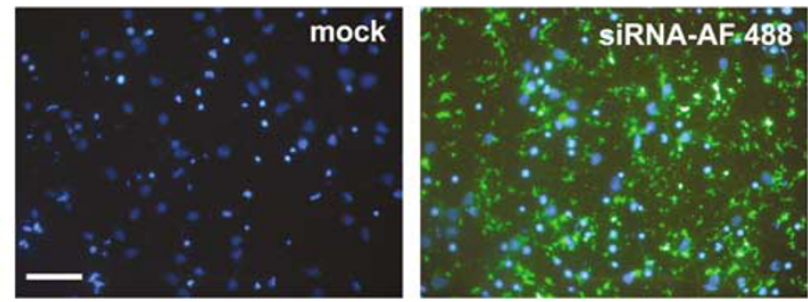

b

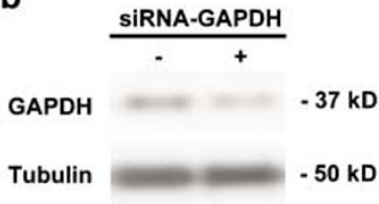

C

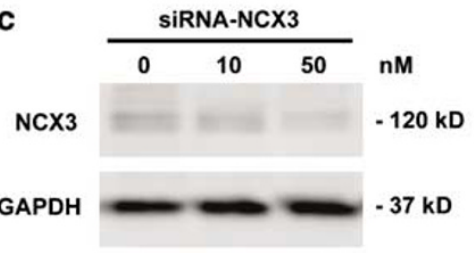

d

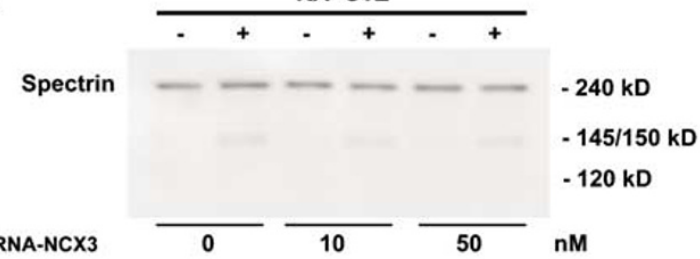

e

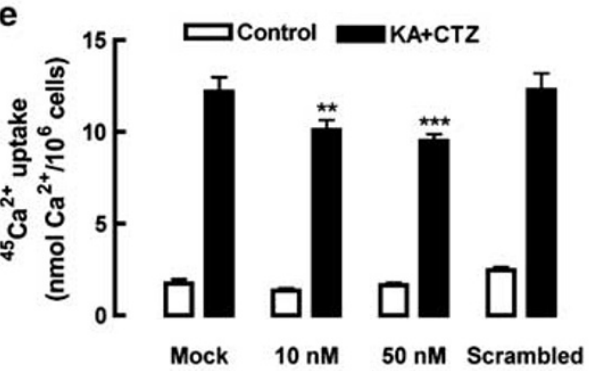

f

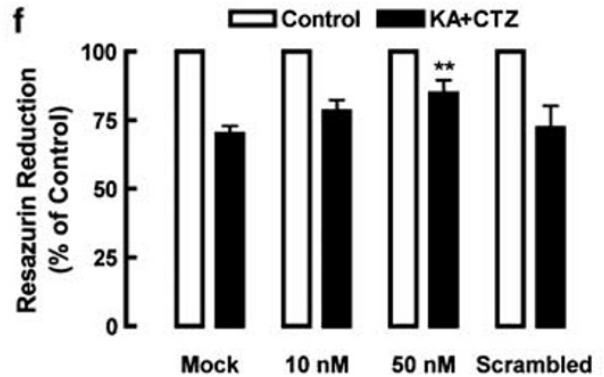

Figure 8 Silencing of NCX3 by delivery of siRNA in hippocampal neurons. (a) High efficiency of transfection of hippocampal neurons with a non-silencing siRNA conjugated with Alexa Fluor 488 (green), at 7 days in vitro, following $48 \mathrm{~h}$ of transfection. Cell nuclei are stained with Hoechst 33342 (blue). Scale bar, $50 \mu \mathrm{m}$. (b) Effective silencing of GAPDH in cultured hippocampal neurons, at 7 days in vitro, using $10 \mathrm{nM}$ of siRNA-GAPDH. Representative Western blots are shown for GAPDH and a control protein (tubulin). (c) Effective silencing of NCX3 by siRNA-NCX3, at 7 days in vitro, following $48 \mathrm{~h}$ of transfection. Representative Western blots are shown for NCX3 and a control protein (GAPDH). (d) Silencing of NCX3 partially prevented spectrin breakdown, following exposure to KA plus CTZ for $5 \mathrm{~min}$. Lysates were prepared $1 \mathrm{~h}$ after exposure to the drugs, and a representative Western blot is shown. (e) siRNA-NCX3 attenuated ${ }^{45} \mathrm{Ca}^{2+}$ uptake stimulated by KA plus CTZ, in a concentration-dependent manner, while a control non-silencing siRNA (referred to as scrambled, in the figure, $50 \mathrm{nM}$ ) had no effect. The results are presented as nanomoles $\mathrm{Ca}^{2+} / 10^{6} \mathrm{cells}$, using means $\pm S . E . M$. of at least four independent experiments. ${ }^{* *} P<0.01,{ }^{* \star *} P<0.001$, significantly different from mock-transfected cells; two-factor ANOVA, Bonferroni's post-test. (f) siRNA-NCX3 reduced the decrease in cell viability observed $24 \mathrm{~h}$ after exposure to KA plus CTZ $(5 \mathrm{~min})$, as assessed by the resazurin reduction assay. The results are presented as percentage of control, using means \pm S.E.M. of at least four independent experiments. ${ }^{* \star} P<0.01$, significantly different from mock-transfected cells; two-factor ANOVA, Bonferroni's post-test

neurons were visualized and counted using a fluorescence microscope (Axioskop 2 Plus, Zeiss, Oberkochen, Germany) and the images were acquired with the Axiovision software 4.2 (Zeiss).

Western blot analysis. The cells were washed and lysed at $4^{\circ} \mathrm{C}$ in $50 \mathrm{mM}$ $\mathrm{KCl}, 50 \mathrm{mM}$ PIPES, $10 \mathrm{mM}$ EGTA, $2 \mathrm{mM} \mathrm{MgCl} 2,0.5 \%$ Triton X-100, supplemented with $100 \mu \mathrm{M}$ PMSF, $1 \mathrm{mM}$ dithiothreitol, $1 \mu \mathrm{g} / \mathrm{ml}$ chymostatin, $1 \mu \mathrm{g} / \mathrm{ml}$ leupeptin, $1 \mu \mathrm{g} / \mathrm{ml}$ antiparin, $5 \mu \mathrm{g} / \mathrm{ml}$ pepstatin $\mathrm{A}, \mathrm{pH} 7.4$, at $4^{\circ} \mathrm{C}$. Protein concentration was determined by the Bradford/BioRad method, ${ }^{24}$ and the samples were used for Western blot analysis, after adding $6 \times$ concentrated sample buffer $(0.5 \mathrm{M}$ Tris, $30 \%$ glycerol, $10 \%$ SDS, $0.6 \mathrm{M}$ dithiothreitol, $0.012 \%$ bromophenol blue) and heating, for $5 \mathrm{~min}$, at $95^{\circ} \mathrm{C}^{17}$

Equal amounts of protein were separated by electrophoresis on SDSpolyacrylamide gels (SDS-PAGE), and transferred electrophoretically to PVDF membranes. These were then blocked for $1 \mathrm{~h}$ at room temperature, in Tris-buffered saline $(137 \mathrm{mM} \mathrm{NaCl}, 20 \mathrm{mM}$ Tris- $\mathrm{HCl}, \mathrm{pH} 7.6)$ containing $0.1 \%$ Tween 20 (TBS-T) and $5 \%$ low-fat milk. Incubations with the primary antibodies (mouse monoclonal anti-nNOS 1:2000; mouse monoclonal anti-spectrin 1:2500; rabbit polyclonal anti-GluR1 1:500; rabbit polyclonal anti-NSBDP 1:300; ${ }^{38}$ mouse anti-NCX1 1:100, clone R3F1 (kind gift from Dr Kenneth Philipson); mouse anti-NCX2 1:50, clone W1C3 (kind gift from Dr Harmut Porzig) and rabbit anti-NCX3 1:250 (kind gift from Dr Kenneth Philipson)) in TBS-T 1\% low-fat milk were performed overnight, at $4^{\circ} \mathrm{C}$. After extensive washing in TBS-T $0.5 \%$ low-fat milk, the membranes were incubated for $1 \mathrm{~h}$ at room temperature with an alkaline phosphatase-linked secondary antibody (anti-mouse or anti-rabbit IgG 1:20 000 in TBS-T 1\% low-fat milk). Immunoreactive bands were visualized by ECF with a VersaDoc 3000 (BioRad, Hercules, CA, USA), following incubation of the membrane with ECF reagent for $5 \mathrm{~min}$. Membrane reprobing was performed using GAPDH (1:5000; Chemicon, Temecula, CA, USA) or tubulin (1:5000; Sigma) labelling as a control for protein loading.

Immunocytochemistry. The culture medium was removed from the primary hippocampal cultures and the cells were washed three times with PBS, and fixed with $4 \%$ paraformaldehyde, at room temperature, for $20 \mathrm{~min}$. Nonspecific binding was blocked with $3 \%$ bovine serum albumin (BSA) in PBS for $1 \mathrm{~h}$. For staining of calpain-mediated SBDPs in neurons, ${ }^{11}$ the cells were incubated with mouse antiMAP2 (1:250), together with rabbit anti-SBDP (1:100), followed by incubation with the appropriate secondary antibodies, anti-rabbit IgG labelled with Alexa Fluor 488 (1:200) for SBDPs, and anti-mouse IgG labelled with Alexa Fluor 594 (1:200) for MAP-2, at room temperature, for $1 \mathrm{~h}$. Finally, the coverslips were mounted using Dako fluorescent mounting medium. The cells were visualized using a fluorescence microscope (Axioskop 2 Plus, Zeiss) and the images were acquired with the Axiovision software 4.2.

${ }^{45} \mathrm{Ca}^{2+}$ uptake experiments. The entry of $\mathrm{Ca}^{2+}$ from the extracellular milieu into the cytosol was investigated by measurement of ${ }^{45} \mathrm{Ca}^{2+}$ uptake, as previously described. ${ }^{25}$ To measure the initial $\mathrm{Ca}^{2+}$ uptake upon stimulation with 


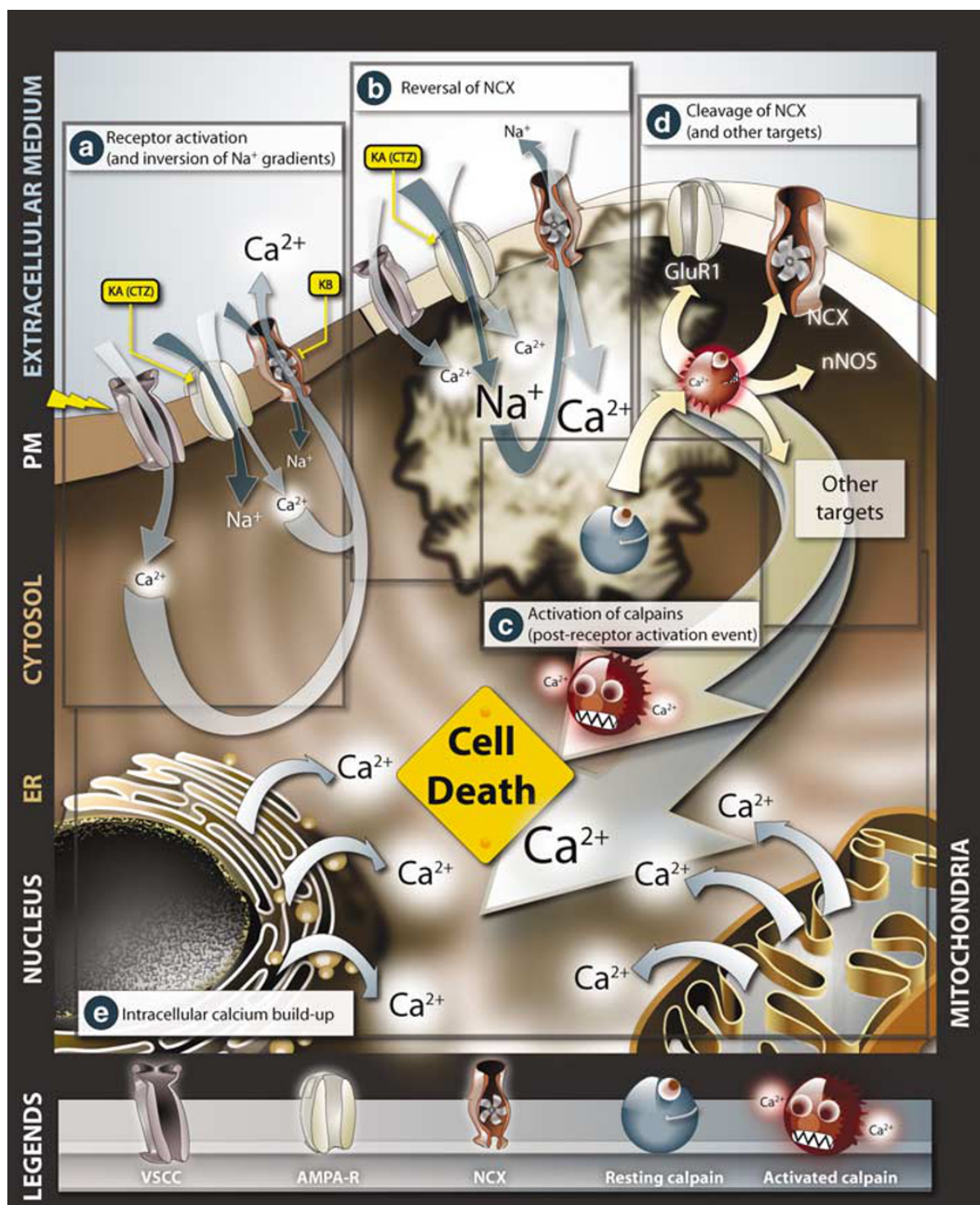

Figure 9 Cellular events in response to activation of AMPA receptors and reversal of NCX in hippocampal neurons. Activation of AMPA receptors by KA, in nondesensitizing conditions (CTZ present), causes entry of $\mathrm{Na}^{+}$through the receptor channel, leading to membrane depolarization; this induces $\mathrm{Ca}^{2+}$ entry into the cell, mainly by VSCC, although some $\mathrm{Ca}^{2+}$ may also permeate the receptor ${ }^{36}(\mathrm{a})$. In resting state, the NCX is working in the forward mode, pumping $\mathrm{Na}^{+}$into the cell and extruding $\mathrm{Ca}^{2+}$. However, due to continuous agonist binding, the $\mathrm{Na}^{+}$concentration inside the cell becomes sufficient to revert the $\mathrm{Na}^{+}$gradient, and then NCX starts working in the reverse mode, pumping $\mathrm{Ca}^{2+}$ in, in exchange for $\mathrm{Na}^{+}$, contributing to the initial rise in intracellular $\mathrm{Ca}^{2+}$ levels $(\mathbf{b})$. Calpains are then activated by this rise in $\mathrm{Ca}^{2+}(\mathbf{c})$, and start cleaving several of their endogenous cellular substrates, like GluR1, nNOS and NCX3, as well as a plethora of other targets (d). The cleavage of NCX by calpains impairs the process of normal calcium extrusion from the cell, and can contribute to a secondary delayed increase in intracellular $\mathrm{Ca}^{2+}$, which may be released from other sources, such as the ER and the mitochondria, contributing to the overall $\mathrm{Ca}^{2+}$ build-up (e). In such conditions, neuronal cell death is inevitable. Blockade of the reversal of NCX with KB-R7943 (KB) decreases the initial $\mathrm{Ca}^{2+}$ entry (a, b), prevents calpain activation (c), cleavage of the $\mathrm{NCX}(\mathbf{d})$, the delayed $\mathrm{Ca}^{2+}$ increase (e) and also prevents cell death, suggesting that the contribution of $\mathrm{NCX}$ reversal in the initial $\mathrm{Ca}^{2+}$ rise is a key event in triggering the cell death cascade

the drugs, cultured hippocampal neurons were preincubated for $10 \mathrm{~min}$ with $1.5 \mu \mathrm{Ci} / \mu \mathrm{mol}{ }^{45} \mathrm{Ca}^{2+}$ (Amersham Pharmacia Biotech, Buckinghamshire, UK) in Krebs buffer, and then incubated for $5 \mathrm{~min}$ with the drugs. The experiment was stopped by aspiration of the medium and addition of ice-cold $\mathrm{Ca}^{2+}$-free Krebs buffer supplemented with $1 \mathrm{mM} \mathrm{LaCl} 3$. The cells were further rinsed twice in $\mathrm{Ca}^{2+}$. free Krebs medium with $1 \mathrm{mM}$ EGTA and then lysed with $1 \mathrm{ml}$ of $\mathrm{H}_{2} \mathrm{O}$ per well. ${ }^{45} \mathrm{Ca}^{2+}$ entering the cells from the outside was analysed in the cell lysate. Universol scintillation liquid ( $2 \mathrm{ml}$; ICN, Irvine, CA, USA) was added to $200 \mu$ l of the lysate and the radioactivity was counted with a Packard 2000 Spectrometer provided with disintegrations per minute (d.p.m.) correction. The results are presented as nanomoles $\mathrm{Ca}^{2}+10^{6}$ cells. All experiments were performed in duplicate in at least three independent cell cultures.
Fura-2 fluorescence measurements by video imaging. Hippocampal neurons plated on coverslips at a density of $0.032 \times 10^{6} \mathrm{cells} / \mathrm{cm}^{2}$ were loaded with $5 \mu \mathrm{M}$ Fura-2/AM and $0.02 \%$ Pluronic F-127 for 30 min at $37^{\circ} \mathrm{C}$ in Krebs buffer supplemented with $0.1 \%$ bovine BSA $(\mathrm{w} / \mathrm{v}){ }^{16}$ After the incubation, the coverslips were rinsed with Krebs buffer and placed in a perfusion chamber on the stage of an inverted Axiovert 200 (Zeiss) fluorescence microscope, equipped with a $\times 40$ oil-immersion objective. The cells were then perfused with Krebs buffer for $5 \mathrm{~min}$, and then stimulated with KA plus CTZ, in the presence or absence of $\mathrm{KB}-\mathrm{R} 7943$, for $5 \mathrm{~min}$ (in Krebs buffer, also in perfusion), and then continuously perfused with Krebs buffer for $60 \mathrm{~min}$. Fluorescence ratio measurements were acquired with excitation at 340 and $380 \mathrm{~nm}$, and emission above $510 \mathrm{~nm}$, and the data are expressed as the fluorescence ration 340/380, as described 
elsewhere. ${ }^{14,29}$ Image analysis was performed using the software MetaFluor 5.0r2 (Universal Imaging Corporation). The neurons that showed a delayed increase of 0.07 in the $340 / 380$ fluorescence ratio (which corresponds to an increase of $17.5 \%$ of the overall free cytosolic $\mathrm{Ca}^{2+}$, compared to the maximum mean peak increase of 0.41 in the condition of KA plus CTZ alone) were considered as having a delayed increase in $\left[\mathrm{Ca}^{2+}\right]$.

siRNA transfection. To determine transfection efficacy, we used a nonsilencing Alexa Fluor 488-conjugated siRNA control, sequence AAT TCT CCG AAC GTG TCA CGT, conjugated with Alexa Fluor 488 (Qiagen, Hilden, Germany; cat. $\# 1027284)$. We observed approximately $90 \%$ of transfected cells.

The siRNA against NCX3 (GenBank accession number NM_079620) was obtained as a siGENOME SMARTpool, consisting of FOUR duplexes that target different regions of the open reading frame (Dharmacon, Thermo Fisher Scientific, Lafayette, CO, USA; cat. \# M-094821-00). As a negative control, a non-silencing scrambled siRNA sequence was used (siRNA Negative Control \#1; Ambion Inc., cat. \# 4610). siRNA-GAPDH was used as a positive control for silencing, during optimization of the transfection conditions (GAPDH siRNA; Ambion Inc., cat. \# 4624).

After 5 days in culture, the hippocampal neurons were transfected with 10 or $50 \mathrm{pmol}$ siRNA (NCX3), using the INTERFERin siRNA Transfection Reagent (PolyPlus Transfection Inc., San Marcos, CA, USA), following the manufacturer's instructions. In brief, siRNA and INTERFERin were mixed together in $200 \mu \mathrm{l}$ of Neurobasal medium for $10 \mathrm{~min}$. Cells were overlaid with the transfection mix for $48 \mathrm{~h}$. Transfected cells were used for calcium uptake experiments, assessment of cell viability and Western blot analysis, 7 days after plating, according to the methods described above.

Data analysis. Data are expressed as means \pm S.E.M. Statistical significance was determined by using two-tailed $t$-tests, one- or two-factor analysis of variance (ANOVA), followed by Bonferroni's post-tests, as indicated in the figure legends and in the text.

Acknowledgements. This work was supported by the Calouste Gulbenkian Foundation, the Foundation for Science and Technology (FCT, Portugal) and FEDER: Inês Araújo was supported by a fellowship from FCT, Portugal (SFRH/ BPD/17196/2004), and by the European Neuroscience Institutes (ENI) Network. The authors would like to thank $\mathrm{Dr}$ Carlos Duarte for helpful discussion on the data, Dr Kenneth Philipson (Los Angeles, CA, USA) and Dr Harmut Porzig (Bern, Switzerland) for the kind gift of the antibodies against NCX subtypes and for critically reading the manuscript, and appreciate the excellent technical assistance of Fátima Graça.

1. Blaustein MP, Lederer WJ. Sodium/calcium exchange: its physiological implications. Physiol Rev 1999; 79: 763-854.

2. Philipson KD, Nicoll DA, Ottolia M, Quednau BD, Reuter $\mathrm{H}$, John $\mathrm{S}$ et al. The $\mathrm{Na}^{+} / \mathrm{Ca}^{2+}$ exchange molecule: an overview. Ann N Y Acad Sci 2002; 976: 1-10.

3. Bers DM. Cardiac $\mathrm{Na} / \mathrm{Ca}$ exchange function in rabbit, mouse and man: what's the difference? J Mol Cell Cardiol 2002; 34: 369-373.

4. Nicoll DA, Longoni S, Philipson KD. Molecular cloning and functional expression of the cardiac sarcolemmal $\mathrm{Na}(+)-\mathrm{Ca} 2+$ exchanger. Science 1990; 250: 562-565.

5. Li Z, Matsuoka S, Hryshko LV, Nicoll DA, Bersohn MM, Burke EP et al. Cloning of the NCX2 isoform of the plasma membrane $\mathrm{Na}(+)-\mathrm{Ca} 2+$ exchanger. J Biol Chem 1994; 269: 17434-17439.

6. Nicoll DA, Quednau BD, Qui Z, Xia YR, Lusis AJ, Philipson KD. Cloning of a third mammalian Na+-Ca2+ exchanger, NCX3. J Biol Chem 1996; 271: 24914-24921.

7. Goll DE, Thompson VF, Li H, Wei W, Cong J. The calpain system. Physiol Rev 2003; 83 : 731-801.

8. Neumar RW, Xu YA, Gada H, Guttmann RP, Siman R. Cross-talk between calpain and caspase proteolytic systems during neuronal apoptosis. J Biol Chem 2003; 278: 1416214167

9. Mattson MP. Excitotoxic and excitoprotective mechanisms: abundant targets for the prevention and treatment of neurodegenerative disorders. Neuromolecular Med 2003; 3 65-94.

10. Lankiewicz S, Marc Luetjens C, Truc Bui N, Krohn AJ, Poppe M, Cole GM et al. Activation of calpain I converts excitotoxic neuron death into a caspase-independent cell death. J Biol Chem 2000; 275: 17064-17071.

11. Araujo IM, Verdasca MJ, Leal EC, Bahr BA, Ambrosio AF, Carvalho AP et al. Early calpainmediated proteolysis following AMPA receptor activation compromises neuronal survival in cultured hippocampal neurons. J Neurochem 2004; 91: 1322-1331.
12. Bahr BA, Bendiske J, Brown QB, Munirathinam S, Caba E, Rudin M et al. Survival signaling and selective neuroprotection through glutamatergic transmission. Exp Neurol 2002; 174 37-47.

13. Chan SL, Mattson MP. Caspase and calpain substrates: roles in synaptic plasticity and cell death. J Neurosci Res 1999; 58: 167-190.

14. Bano D, Young KW, Guerin CJ, Lefeuvre R, Rothwell NJ, Naldini L et al. Cleavage of the plasma membrane $\mathrm{Na}+/ \mathrm{Ca} 2+$ exchanger in excitotoxicity. Cell 2005; 120: 275-285.

15. Gomez-Villafuertes R, Torres B, Barrio J, Savignac M, Gabellini N, Rizzato F et al. Downstream regulatory element antagonist modulator regulates $\mathrm{Ca} 2+$ homeostasis and viability in cerebellar neurons. J Neurosci 2005; 25: 10822-10830.

16. Ambrósio AF, Silva AP, Malva JO, Mesquita JF, Carvalho AP, Carvalho CM. Role of desensitization of AMPA receptors on the neuronal viability and on the $[\mathrm{Ca} 2+]_{i}$ changes in cultured rat hippocampal neurons. Eur J Neurosci 2000; 12: 2021-2031.

17. Araujo IM, Ambrosio AF, Leal EC, Santos PF, Carvalho AP, Carvalho CM. Neuronal nitric oxide synthase proteolysis limits the involvement of nitric oxide in kainate-induced neurotoxicity in hippocampal neurons. J Neurochem 2003; 85: 791-800.

18. Rego AC, Monteiro NM, Silva AP, Gil J, Malva JO, Oliveira CR. Mitochondrial apoptotic cell death and moderate superoxide generation upon selective activation of non-desensitizing AMPA receptors in hippocampal cultures. J Neurochem 2003; 86: 792-804.

19. Partin KM, Patneau DK, Winters CA, Mayer ML, Buonanno A. Selective modulation of desensitization at AMPA versus kainate receptors by cyclothiazide and concanavalin $A$ Neuron 1993; 11: 1069-1082.

20. Santos AE, Carvalho AL, Lopes MC, Carvalho AP. Differential postreceptor signaling events triggered by excitotoxic stimulation of different ionotropic glutamate receptors in retinal neurons. J Neurosci Res 2001; 66: 643-655.

21. Iwamoto $\mathrm{T}$, Shigekawa M. Differential inhibition of $\mathrm{Na}+/ \mathrm{Ca} 2+$ exchanger isoforms by divalent cations and isothiourea derivative. Am J Physiol 1998; 275: C423-C430.

22. Brewer GJ, Torricelli JR, Evege EK, Price PJ. Optimized survival of hippocampal neurons in B27-supplemented Neurobasal, a new serum-free medium combination. J Neurosci Res 1993; 35: 567-576.

23. Mosmann T. Rapid colorimetric assay for cellular growth and survival: application to proliferation and cytotoxicity assays. J Immunol Methods 1983; 65: 55-63.

24. Bradford MM. A rapid and sensitive method for the quantitation of microgram quantities of protein utilizing the principle of protein-dye binding. Anal Biochem 1976; 72: 248-254.

25. Ferreira IL, Duarte CB, Carvalho AP. Kainate-induced retina amacrine-like cell damage is mediated by AMPA receptors. Neuroreport 1998; 9: 3471-3475

26. Iwamoto $T$, Inoue $Y$, Ito $K$, Sakaue $T$, Kita $S$, Katsuragi $T$. The exchanger inhibitory peptide region-dependent inhibition of $\mathrm{Na}+\mathrm{Ca} 2+$ exchange by $\mathrm{SN}-6$ thiazolidine-4 carboxylic acid ethyl ester], a novel benzyloxyphenyl derivative. Mol Pharmacol 2004; 66: $45-55$.

27. Almeida RD, Manadas BJ, Melo CV, Gomes JR, Mendes CS, Graos MM et al. Neuroprotection by BDNF against glutamate-induced apoptotic cell death is mediated by ERK and PI3-kinase pathways. Cell Death Differ 2005; 12: 1329-1343.

28. Nicholls DG, Ward MW. Mitochondrial membrane potential and neuronal glutamate excitotoxicity: mortality and millivolts. Trends Neurosci 2000; 23: 166-174.

29. Rego AC, Ward MW, Nicholls DG. Mitochondria control ampa/kainate receptor-induced cytoplasmic calcium deregulation in rat cerebellar granule cells. J Neurosci 2001; 21 1893-1901.

30. Vergun O, Keelan J, Khodorov BI, Duchen MR. Glutamate-induced mitochondrial depolarisation and perturbation of calcium homeostasis in cultured rat hippocampal neurones. J Physiol 1999; 519 (Part 2): 451-466.

31. Ward MW, Rego AC, Frenguelli BG, Nicholls DG. Mitochondrial membrane potential and glutamate excitotoxicity in cultured cerebellar granule cells. J Neurosci 2000; 20 7208-7219.

32. Hoyt KR, Arden SR, Aizenman E, Reynolds IJ. Reverse $\mathrm{Na}+/ \mathrm{Ca} 2+$ exchange contributes to glutamate-induced intracellular $\mathrm{Ca} 2+$ concentration increases in cultured rat forebrain neurons. Mol Pharmacol 1998; 53: 742-749.

33. Kim YT, Park YJ, Jung SY, Seo WS, Suh CK. Effects of Na+-Ca2+ exchanger activity on the alpha-amino-3-hydroxy-5-methyl-4-isoxazolone-propionate-induced $\mathrm{Ca} 2+$ influx in cerebellar Purkinje neurons. Neuroscience 2005; 131: 589-599.

34. Sattler R, Charlton MP, Hafner M, Tymianski M. Distinct influx pathways, not calcium load, determine neuronal vulnerability to calcium neurotoxicity. J Neurochem 1998; 71 2349-2364.

35. Adamec E, Beermann ML, Nixon RA. Calpain I activation in rat hippocampal neurons in culture is NMDA receptor selective and not essential for excitotoxic cell death. Brain Res Mol Brain Res 1998; 54: 35-48.

36. Arundine $M$, Tymianski M. Molecular mechanisms of calcium-dependent neurodegeneration in excitotoxicity. Cell Calcium 2003; 34: 325-337.

37. Guerini D, Coletto L, Carafoli E. Exporting calcium from cells. Cell Calcium 2005; 38 : 281-289.

38. Bahr BA, Tiriveedhi S, Park GY, Lynch G. Induction of calpain-mediated spectrin fragments by pathogenic treatments in long-term hippocampal slices. J Pharmacol Exp Ther 1995; 273: $902-908$.

39. Thurneysen T, Nicoll DA, Philipson KD, Porzig H. Immunohistochemical detection of the sodium-calcium exchanger in rat hippocampus cultures using subtype-specific antibodies. Ann N Y Acad Sci 2002; 976: 367-375. 